\section{NASA TECHNICAL MEMORANDUM}

م్

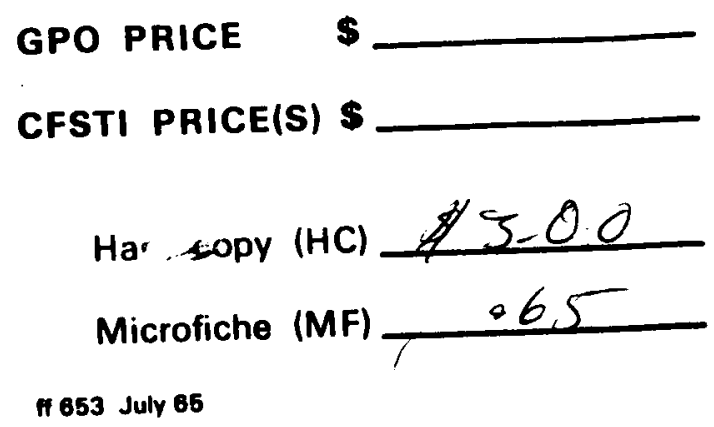

\title{
ESTIMATING RELIABILITY OF COMPLEX SYSTEMS
}

By Robert H. Ailor

Quality and Reliability Assurance Laboratory

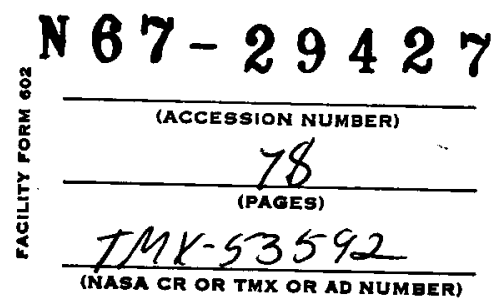

NASA TM X-53592

June 9, 1967

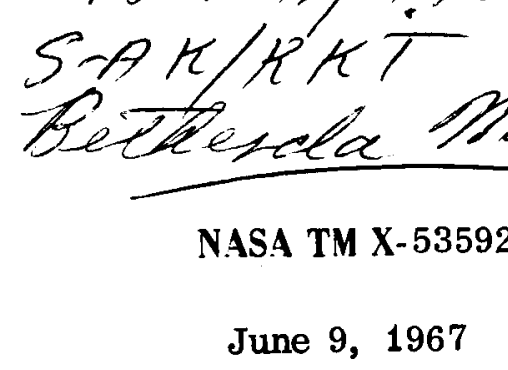


TECHNICAL MEMORANDUM TM X -53592

\author{
ESTIMATING RELIABILITY OF COMPLEX SYSTEMS \\ By \\ Robert H. Ailor \\ George C. Marshall Space Flight Center \\ Huntsville, Alabama
}

\begin{abstract}
This study is confined to a subproblem of a major problem. The major problem is viewed as that of selecting a particular design from several proposed design concepts. The subproblem treated here is that of estimating the reliability of the proposed concepts, with particular emphasis on complex systems.

In the area of complex systems, two methods are presented, and the conditions under which these methods can be used are discussed.
\end{abstract}


NASA - GEORGE C. MARSHALL SPACE FLIGHT CENTER

TECHNICAL MEMORANDUM TM X -53592

ESTIMATING RELIABILITY OF COMPLEX SYSTEMS

By

Robert H. Ailor

\author{
RELIABILITY ENGINEERING BRANCH \\ RELIABILITY ASSURANCE DIVISION \\ QUALITY AND RELIABILITY ASSURANCE LABORATORY
}


I. SELECTION OF A SYSTEM DESIGN .......... 2

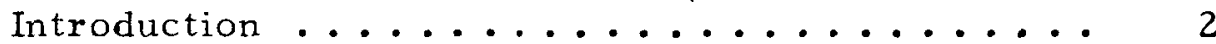

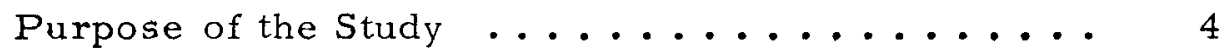

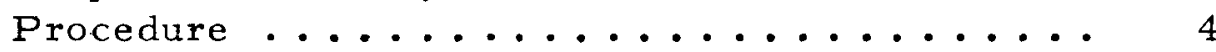

II. ANALYSIS OF SIMPLE SYSTEMS ........... 6

Simple Systems Defined ................... 6

Construction of a Reliability Logic Diagram .... 7

Writing the System Reliability Equation ...... 8

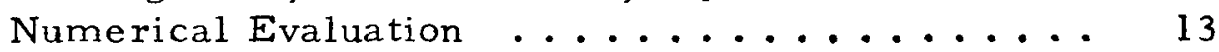

III. ANALYSIS OF COMPLEX SYSTEMS ......... 15

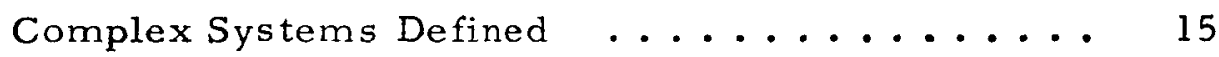

Construction of a Reliability Logic Diagram for a

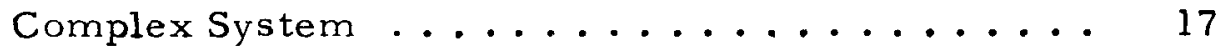

Writing the System Reliability Equation ...... 21

Numerical Evaluation ................. 28

IV. COMPONENT RELIABILITIES ........... 37

Component Reliability Functions ......... 37

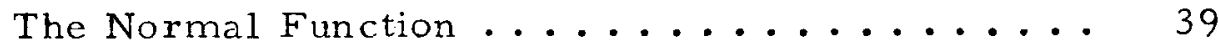

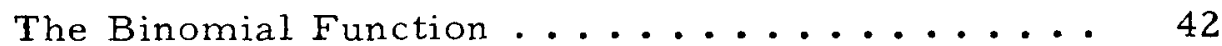

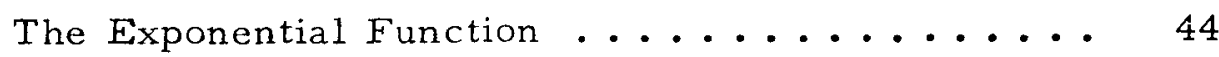

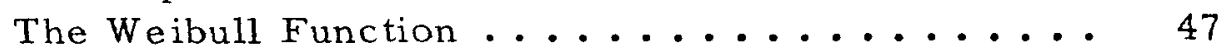

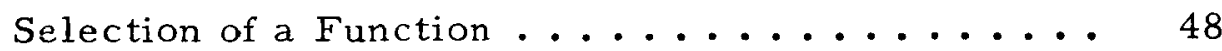

Component Reliabilities for the Electrical

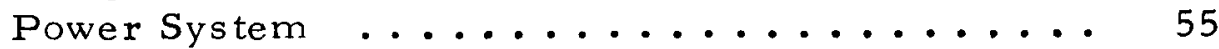

V. FURTHER ANALYSIS OF COMPLEX SYSTEMS ... 57

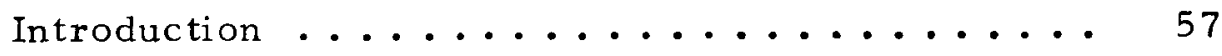

A Method for Determining the System Reliability

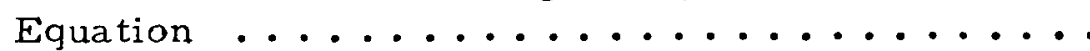

Application of the Method to the Electrical Power

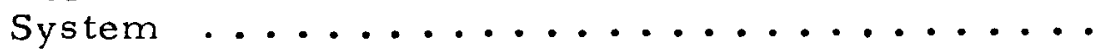


TABLE OF CONTENTS (Continued)

Chapter

Page

VI. IMPLEMENTING, CONTROLLING, AND TESTING

THE SOLUTION ..................... 64

Implementation and Controls for the Solution .... 64

Testing the Solution ............... 65

VII. CONCLUSIONS AND RECOMMENDATIONS ..... 66

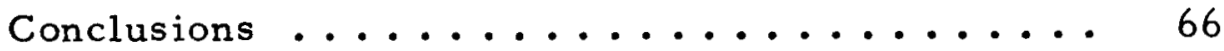

Recommendations ................ 67

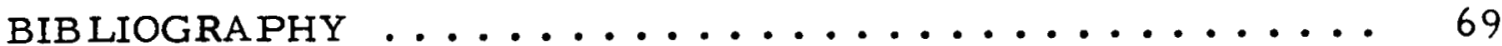




\section{LIST OF ILLUSTRATIONS}

Figure

Page

1. Reliability Logic Diagrams. A: Series Arrangement,

B: Parallel Arrangement ................. 10

2. Reliability Logic Diagrams. A: Series-Parallel

Arrangement, B: Semi-Parallel Arrangement .... 12

3. Electrical Power System (With Optional APU) ..... 16

4. Reliability Logic Diagram for Electrical Power

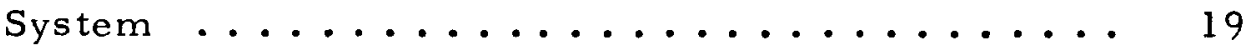

5. Reliability Logic Diagram for a System of a Complex

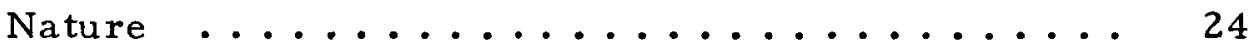

6. Simplified Reliability Logic Diagram for Electrical

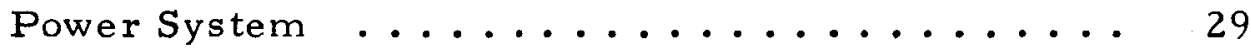

\section{LIST OF TABLES}

Table

I. Determination of Data for Applying Chi-Squa re Test . . 52

II. Data for Applying Chi-Square Test .......... 54

III. Component Data for Electrical Power System . . . . 56 


\author{
ESTIMATING RELIABILITY OF COMPLEX SYSTEMS \\ By \\ Robert H. Ailor
}

\title{
SUMMARY
}

This study is confined to a subproblem of a major problem. The major problem is viewed as that of selecting a particular design from several proposed design concepts. The subproblem treated here is that of estimating the reliability of the proposed concepts, with particular emphasis on complex systems.

The analysis of simple systems is discussed whereby the system reliability equation can be determined by a relatively easy application of the fundamental probability theorems. For complex systems, two methods are presented. First, a canonical expansion scheme technique is used when the system has a relatively few number of components or the component probabilities of failure are small. If the number of components in a system is rather large and the above conditions do not hold, another method is presented to obtain the complete system reliability equation which depends primarily on defining pertinent output events for the system.

The reliability functions for the components that make up a system are discussed and finally, a limited discussion is provided on implementing, controlling, and testing the solution in regard to reliability. 


\section{CHAPTER I. SELECTION OF A SYSTEM DESIGN}

\section{Introduction}

The selection of a system design can be treated as an engineering management type problem. A situation may exist whereby the engineering manager is confronted with the problem of selecting a particular design from several proposed design concepts.

The nature of the technical decision process is basically the same as any other since it requires recognition of objectives, formulation of criteria for the system to meet these objectives, and selection of rules or strategies for making the choice that will hopefully maximize a payoff. ${ }^{1}$ Criteria for the selection of a design concept from several competing ones might be based on such elements as cost, weight, performance, and reliability.

Thus the major problem is somehow to select one concept out of several based on established criteria. There are methods available to determine how well objectives have been met based on established criteria. This problem can become difficult when two or more quantitative objectives are involved. A measure of efficiency is required for each objective, and a method is required

${ }^{1} J$. M. English, "Understanding the Engineering Design Process," Journal of Industrial Engineering, Volume XV, Number 6, 1964, p. 291. 
for transforming units on each efficiency scale into one standard scale with a relative value of points on this scale. ${ }^{2}$

In many situations, a limitation of resources precludes the necessary effort to make the required transformations. In such cases a common procedure is to select one of the most important objectives as a basis for measuring the performance of each course of action. Minimum levels of performance for the other elements are imposed as restrictions for an acceptable solution. ${ }^{3}$

Determining the value of each of the elements on which the criteria is based presents subproblems of the major problem. Estimating the reliability of each design concept is such a subproblem, the objective of which is to maximize the reliability, which is also the associated measure of efficiency. Several different system design concepts, each representing a course of action. may be under consideration. Many such systems are of a complex nature. The reliability of each system concept is estimated, and the one having the highest value is presented as the best candidate from the standpoint of reliability. For the purposes of this study, reliability may be defined as the probability that some desired event will occur.

${ }^{2}$ R. L. Ackoff, Scientific Method, John Wiley \& Sons, Inc., New York, N. Y., 1962 , p. 77.

3Tbid., p. 105. 


\section{Purpose of the Study}

The objective of this study is to develop a method for estimating the reliability of complex systems. The term complex system is used to indicate a functional system of such a nature that the reliability of it cannot easily be estimated by application of the fundamental probability theorems. A complex system as defined here can also be thought of as composed of a number of components such that when a reliability logic diagram is constructed for the purposes of making a probability analysis, the diagram does not result in a series, parallel, or series-parallel arrangement of the components. The reliability logic diagrams will be discussed further in Chapter II.

\section{$\underline{\text { Procedure }}$}

Analysis of simple systems will be discussed first. This will consist of constructing a reliability logic diagram and applying the basic probability theorems to obtain an equation which expresses the reliability of the system as a function of the reliabilities of the components which make up the system.

A complex system will then be discussed using an electrical power distribution system as an example. A system functional block diagram will be used to construct a reliability logic diagram, and a method for estimating the reliability under certain conditions will be presented. At this point the reliabilities of the components that make up the system will be discussed. 
Another method for estimating the reliability of a complex system will then be developed. Following this will be a limited discussion on implementing, controlling, and testing the solution. Finally, a summary and recommendations will be presented. 


\section{CHAPTER II. ANALYSIS OF SIMPLE SYSTEMS}

\section{Simple Systems Defined}

When a system is studied for the purpose of making a reliability analysis, a reliability logic diagram is constructed to depict the system. A reliability logic diagram is not a functional schematic of the system. It is instead a diagram showing the reliability relationship of the components that make up the system.

Simple systems are characterized by two basic types of relationships: series and parallel. Components are in series when the failure of any one of them would mean a failure of the system. Components are in parallel when successful operation of at least one of them would not cause failure of the system. Simple systems can also be formed by combinations of these two relationships which provide series-parallel systems. There are also semiparallel situations in which, for example, two out of three components operating successfully would ensure successful operation of a system or a segment of a system.

It is cautioned that these systems are not necessarily simple from a functional standpoint, but simple from a reliability logic standpoint. A system may be highly complicated from a functional standpoint, but it may be 
necessary for every component in the system to work properly in order for the system to work properly. Thus such a system would be a simple series system.

\section{Construction of a Reliability Logic Diagram}

To construct a reliability logic diagram of a system, it is necessary to determine the effect of the fallure of the components that make up the system. This is quite often difficult to do and is best done by the design personnel who are responsible for the system and are most familiar with it. Many times it is performed by people in a reliability group. When this situation arises, it is necessary for the reliability engineer to work very closely with the appropriate design engineer in order to construct the reliability logic diagram.

After the reliability logic diagram is constructed, the system reliability is determined as a function of the reliabilities of the components that make up the system.

This can be accomplished for simple systems by application of the fundamental probability theorems given below.

The Addition Theorem. If $\mathrm{C}_{1}$ and $\mathrm{C}_{2}$ are two events which can occur simultaneously, the probability that either $\mathrm{C}_{1}$ or $\mathrm{C}_{2}$ or both $\mathrm{C}_{1}$ and $\mathrm{C}_{2}$ will occur is

$$
\mathrm{P}\left(\mathrm{C}_{1}+\mathrm{C}_{2}\right)=\mathrm{P}\left(\mathrm{C}_{1}\right)+\mathrm{P}\left(\mathrm{C}_{2}\right)-\mathrm{P}\left(\mathrm{C}_{1} \mathrm{C}_{2}\right),
$$

where $\mathrm{P}\left(\mathrm{C}_{1}+\mathrm{C}_{2}\right)=$ probability that either $\mathrm{C}_{1}$ or $\mathrm{C}_{2}$ or both $\mathrm{C}_{1}$ and $\mathrm{C}_{2}$ will occur, 
$P\left(C_{1}\right)=$ probability that $C_{1}$ occurs,

$\mathrm{P}\left(\mathrm{C}_{2}\right)=$ probability that $\mathrm{C}_{2}$ occurs, and

$\mathrm{P}\left(\mathrm{C}_{1} \mathrm{C}_{2}\right)=$ probability that both $\mathrm{C}_{1}$ and $\mathrm{C}_{2}$ occur.

If the two events are mutually exclusive so that if one occurs the other cannot, the probability that either $\mathrm{C}_{1}$ or $\mathrm{C}_{2}$ occurs is

$$
P\left(C_{1}+C_{2}\right)=P\left(C_{1}\right)+P\left(C_{2}\right)
$$

The Multiplication Theorem. If $\mathrm{C}_{1}$ and $\mathrm{C}_{2}$ are two events, the probability that both occur is

$$
\mathrm{P}\left(\mathrm{C}_{1} \mathrm{C}_{2}\right)=\mathrm{P}\left(\mathrm{C}_{1}\right) \mathrm{P}\left(\mathrm{C}_{2} \mid \mathrm{C}_{1}\right)
$$

where $P\left(C_{2} \mid C_{1}\right)=$ probability that $C_{2}$ occurs, given that $C_{1}$ has occurred.

If $\mathrm{C}_{1}$ and $\mathrm{C}_{2}$ are two independent events such that the occurrence of either is not dependent on the other, then the probability that both occur is

$$
P\left(C_{1} C_{2}\right)=P\left(C_{1}\right) P\left(C_{2}\right){ }^{1}
$$

Writing the System Reliability Equation

To illustrate how the system reliability equation is written for simple systems, several hypothetical systems will be postulated. First, a series system will be used. Suppose a system containing three components has been studied, and it has been determined that every component in it has to operate in order for the system to operate. A reliability logic diagram for such a

${ }^{1}$ P. G. Hoel, Introduction to Mathematical Statistics, John Wiley \& Sons, Inc., New York, N. Y., 1962, pp. 9-11. 
system is shown in Figure 1-A. Assuming the successful operation of each component is an independent event, the system reliability equation is written as

$$
R_{s}=R_{1} \cdot R_{2} \cdot R_{3}
$$

where $R_{S}=$ reliability (probability of success) of the system, $R_{i}=$ reliability of the $i^{\text {th }}$ component, and $i=1,2,3$.

Now consider a system which, after study, results in a parallel reliability logic diagram. It consists of two components, and the successful operation of either component will provide successful system operation. The diagram is shown in Figure 1-B. Assuming again that the successful operations of the components are independent events, the system reliability equation is written as

$$
R_{S}=R_{1}+R_{2}-R_{1} R_{2}
$$

where $R_{S}=$ reliability of the system, and $R_{i}=$ reliability of the $i^{\text {th }}$ component for

$$
\mathbf{i}=1,2 \text {. }
$$

Now since each component operates either successfully or not, the relationship

$$
R_{i}+Q_{i}=1
$$

is valid where $R_{i}=$ the reliability (probability of success) of the $i^{\text {th }}$ component and $Q_{i}=$ the unreliability (probability of fajlure) of the $i^{\text {th }}$ component. With this relationship the system reliability equation can also be written as 


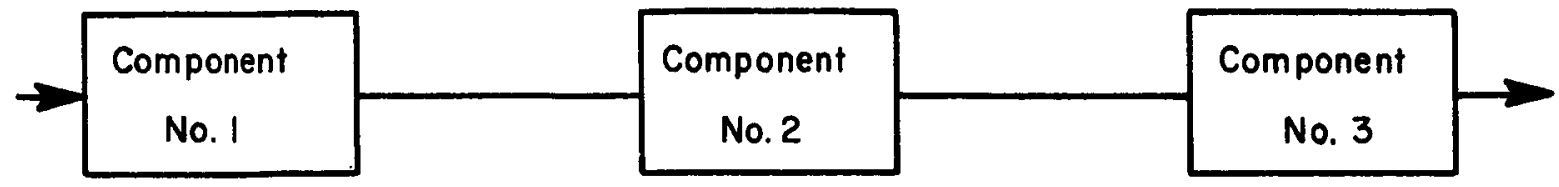

A. Series Arrangement

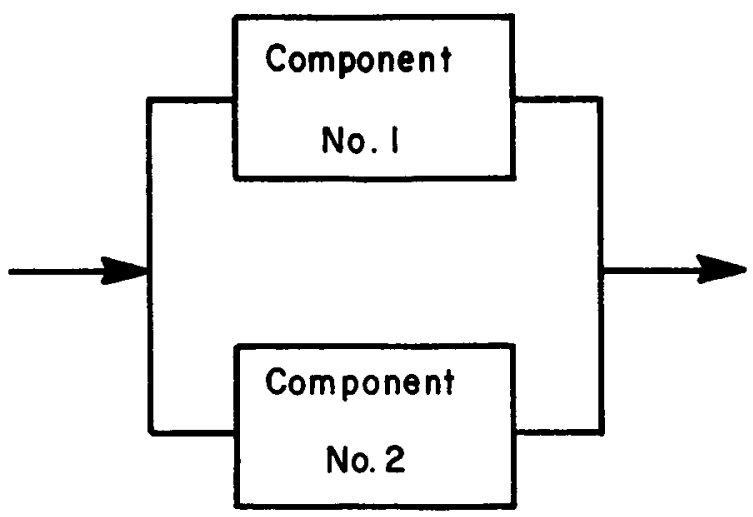

B. Parallel Arrangement

Figure 1. Reliability Logic Diagrams. A: Series Arrangement, B: Parallel Arrangement. 


$$
R_{S}=1-Q_{1} Q_{2}
$$

This can be verified as follows:

$Q_{i}=1-R_{i}$, thus

$Q_{1}=1-R_{1}$, and

$Q_{2}=1-R_{2}$; substituting into the system reliability equation,

$$
\begin{gathered}
R_{S}=1-\left(1-R_{1}\right)\left(1-R_{2}\right)=1-\left(1-R_{2}-R_{1}+R_{1} R_{2}\right) \\
R_{S}=R_{1}+R_{2}-R_{1} R_{2} .
\end{gathered}
$$

This is the same equation obtained previously.

Consider now a system consisting of four components. Assume the system has been studied and that it is concluded that two of the components are redundant (parallel), and that the other two are in series. This results in a series-parallel reliability logic diagram shown in Figure 2-A. If independent probabilities of success for the components are assumed, the system reliability equation is written directly as

$$
R_{S}=R_{1}\left(R_{2}+R_{3}-R_{2} R_{3}\right) R_{4},
$$

where $R_{S}=$ reliability of the system, and $R_{i}=$ reliability of the $i^{\text {th }}$ component for

$$
\mathbf{i}=1,2,3,4 \text {. }
$$

For a semi-parallel system, assume that a system of three identical components has been studied and it has been determined that the system will operate successfully if at least two out of three components operate successfully. 


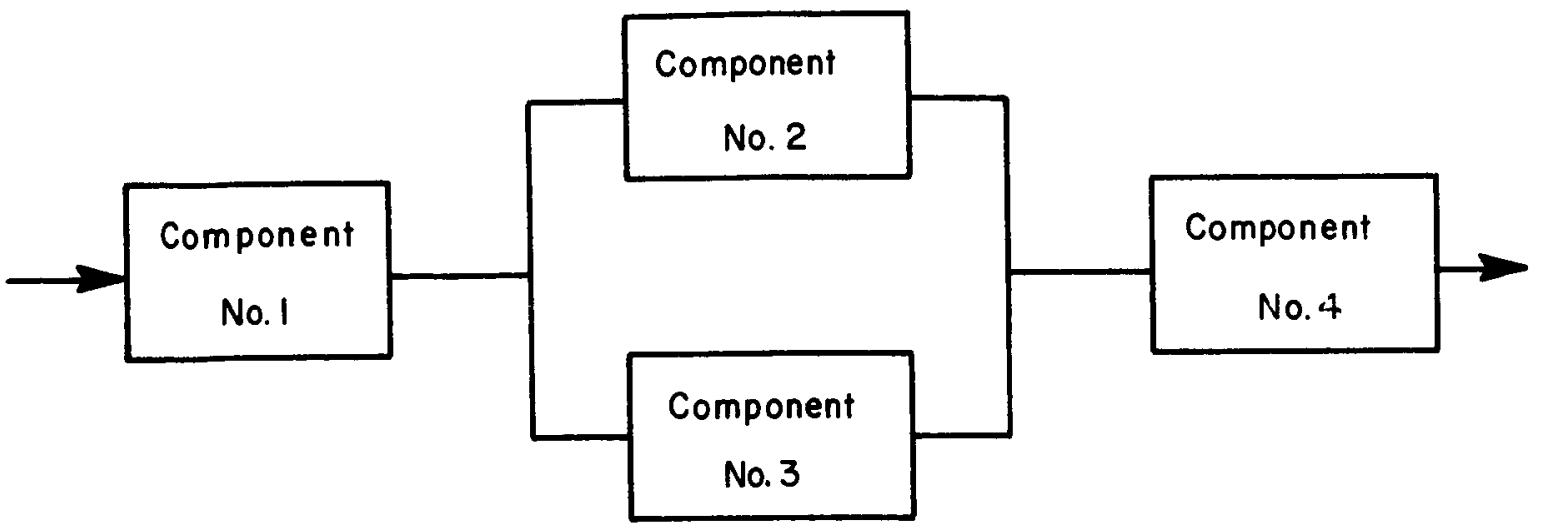

A. Series-parallel Arrangement

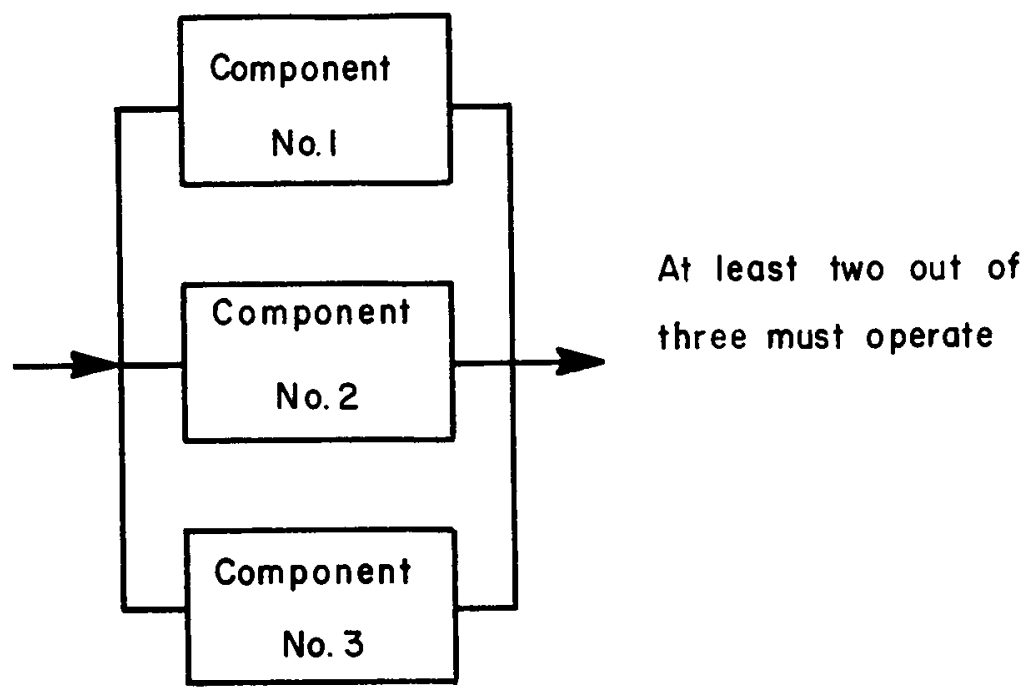

B. Semi-parallel Arrangement

Figure 2. Reliability Logic Diagrams. A: Series-parallel Arrangement, B: Semi-parallel Arrangement. 
The system reliability equation can be written by application of the binomial expansion which is written in compact form ${ }^{2}$ as

$$
(R+Q)^{n}=\sum_{x=0}^{n} \frac{n !}{(n-x) ! x !} R^{n-x} Q^{x} .
$$

For this particular problem,

$\mathrm{n}=3$,

$\mathbf{R}=$ probability of success for each component, and

$Q=$ probability of failure for each component.

Expansion of the compact form gives

$$
\sum_{x=0}^{3} \frac{3 !}{x !(3-x) !} R^{3-x} Q^{x}=R^{3}+3 R^{2} Q+3 R Q^{2}+Q^{3} .
$$

The first two terms of this expansion represent events for which success will be achieved. Thus the system reliability equation is

$$
R_{S}=R^{3}+3 R^{2} Q .
$$

The reliability logic diagram for this system is shown in Figure 2-B.

\section{Numerical Evaluation}

The system reliability is evaluated numerically by direct substitution of the component reliabilities into the system reliability equations. For convenience of illustration, assume that all the components have a reliability of 0.9900 , and thus an unreliability of 0.0100 .

${ }^{2}$ P. G. Hoel, Introduction to Mathematical Statistics, John Wiley \& Sons, Inc., New York, N. Y., 1962, p. 86. 
For the series system, the system equation was

$$
R_{S}=\left(R_{1}\right)\left(R_{2}\right)\left(R_{3}\right) .
$$

By direct substitution,

$$
\begin{gathered}
R_{S}=(0.9900)(0.9900)(0.9900) \\
R_{S}=0.9703 .
\end{gathered}
$$

For the parallel system, the system reliability equation was

$$
R_{S}=R_{1}+R_{2}-R_{1} \cdot R_{2} .
$$

By direct substitution,

$$
\begin{gathered}
R_{S}=0.9900+0.9900-(0.9900)(0.9900) \\
R_{S}=0.9999 .
\end{gathered}
$$

In the series-parallel system, the system reliability equation was

$$
R_{S}=\left(R_{1}\right)\left(R_{2}+R_{3}-R_{2} \cdot R_{3}\right)\left(R_{4}\right) .
$$

By direct substitution,

$$
\begin{gathered}
R_{S}=(0.9900)[0.9900+0.9900-(0.9900)(0.9900)](0.9900) \\
R_{S}=0.9800 .
\end{gathered}
$$

Lastly, the semi-parallel system produced the system reliability equation,

$$
R_{S}=R^{3}+(3)\left(R^{2}\right)(Q) .
$$

By direct substitution,

$$
\begin{gathered}
R_{S}=(0.9900)^{3}+3(0.9900)^{2}(0.0100) \\
R_{S}=0.9997 .
\end{gathered}
$$




\section{CHAPTER III. ANALYSIS OF COMPLEX SYSTEMS}

\section{Complex Systems Defined}

As discussed in Chapter I, the term complex system is used here to indicate a functional system composed of a number of components such that when a reliability logic diagram is constructed for the purpose of making a probability analysis, the diagram does not result in a series, parallel, or series-parallel configuration. Thus the system reliability equation of the complex system cannot readily be written by direct application of the fundamental probability theorems.

The analysis of complex systems will be discussed, with an electrical power distribution system as an example. This electrical power distribution system, shown in Figure 3, is typical of those used in a twin-engine transport or passenger airplane. This might be one of several proposed systems being considered.

For each proposed system, it is usually desirable that comparison be made on the basis of the probability of achieving several desired events. Some of these events would be:

1. Having power available during flight to at least one $\mathrm{AC}$ bus and at least one DC bus,

2. Having power available during flight to the emergency $\mathrm{AC}$ bus and the emergency DC bus, and 


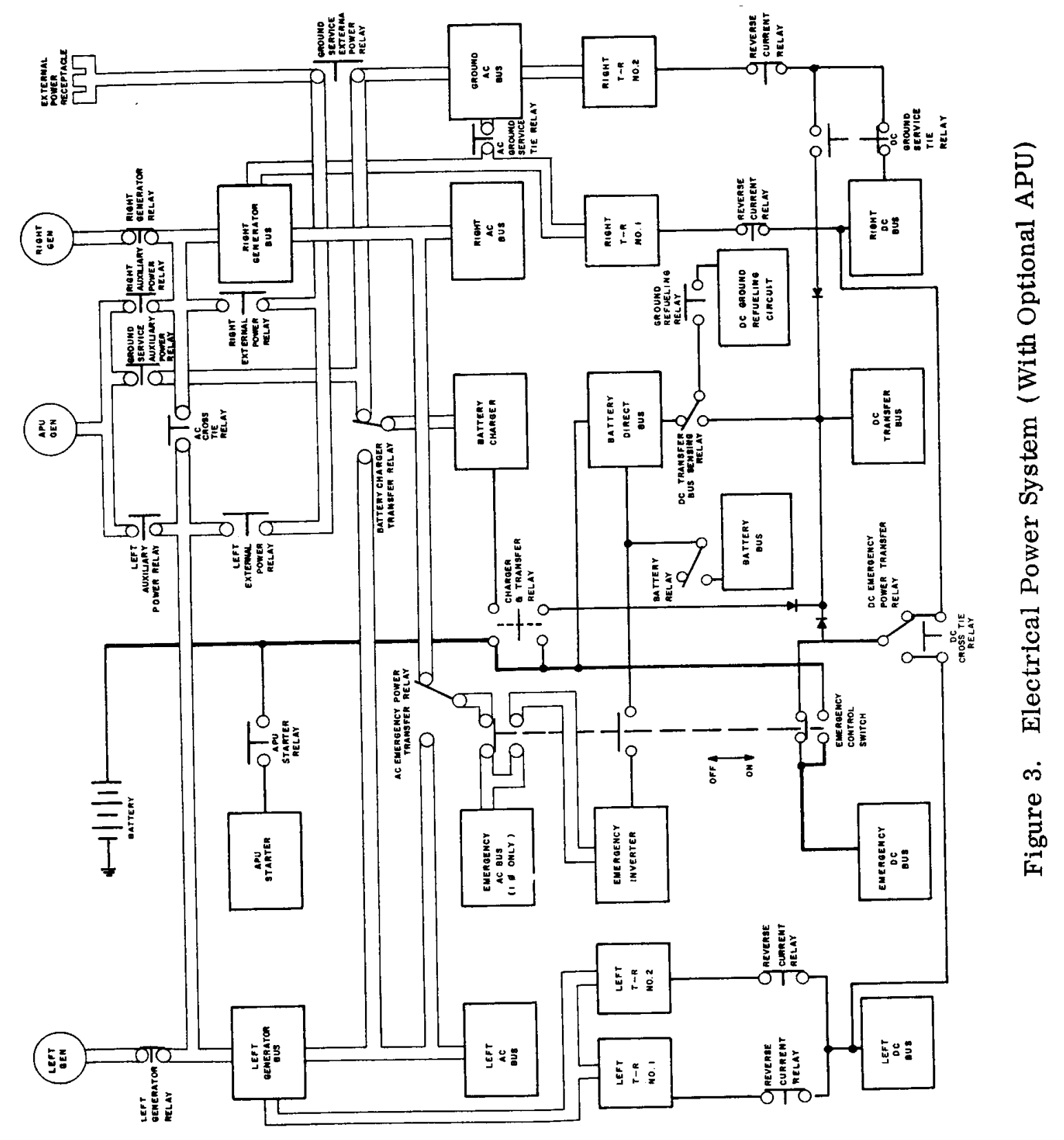


3. Having the capability to dispatch under Federal Aviation Agency (FAA) regulations.

\section{Construction of a Reliability Logic Diagram for a Complex System}

The construction of a reliability logic diagram for a complex system is performed in the same general manner as for a simple system; however, it is much more difficult. Initially, the event which is of concern must be defined. The immediate objective here is to estimate the probability that this event will occur (or the probability that it will not occur). As discussed in Chapter II, it is necessary to determine the effect of the failure of the components that make up the system. This requires a thorough understanding of how the system operates. Thus, for expediency, the assistance of one of the system design engineers must be readily available.

No attempt will be made here to give a description of how the electrical power distribution system operates as that is not the primary purpose of this study. However, it is necessary to point out at least one major feature of the system operation. The various buses have the electrical loads divided among them in such a manner that the complete loss of one AC bus and one DC bus will not adversely affect the operation of the airplane. ${ }^{1}$

Subsequently, to develop the method of analysis, the reliability logic diagram will be constructed with the objective of estimating the probability

${ }^{1}$ DC-9 Electrical System Fault Analysis, Engineering Report No. LB-32161, Douglas Aircraft Co., Long Beach, California, April, 1965, p. 3.11 . 
of occurrence of the following event: having power available during flight to at least one $\mathrm{AC}$ bus and at least one $\mathrm{DC}$ bus. This will also be referred to as the reliability of the system. In other words, system reliability is equal to the probability of having power available during flight to at least one AC bus and at least one DC bus.

The reliability logic diagram is shown in Figure 4. This diagram is constructed from studying the system functional block diagram shown in Figure 3, and by drawing, if necessary, on the knowledge of the appropriate design engineer. The diagram reveals that there are several possible paths for making power available to the left and right $\mathrm{AC}$ buses and the left and right $\mathrm{DC}$ buses. To avoid overcomplicating the analysis, the study will be made assuming a system without the optional auxiliary power unit (APU). Also independent probabilities of success for the components will be assumed. If sufficient information was available and it was determined that some of the probabilities were dependent, then the dependent probabilities would be used. It is also assumed that mechanical power is available to drive the generators. Although it is difficult to provide specific rules for constructing a reliability logic diagram such as Figure 4 from an operational or functional block diagram such as Figure 3, it is worthwhile to discuss the approach for doing so. As mentioned previously, the operational diagram in Figure 3 reveals that there are several possible paths for making power available to the left and right $\mathrm{AC}$ buses and the left and right $\mathrm{DC}$ buses. 


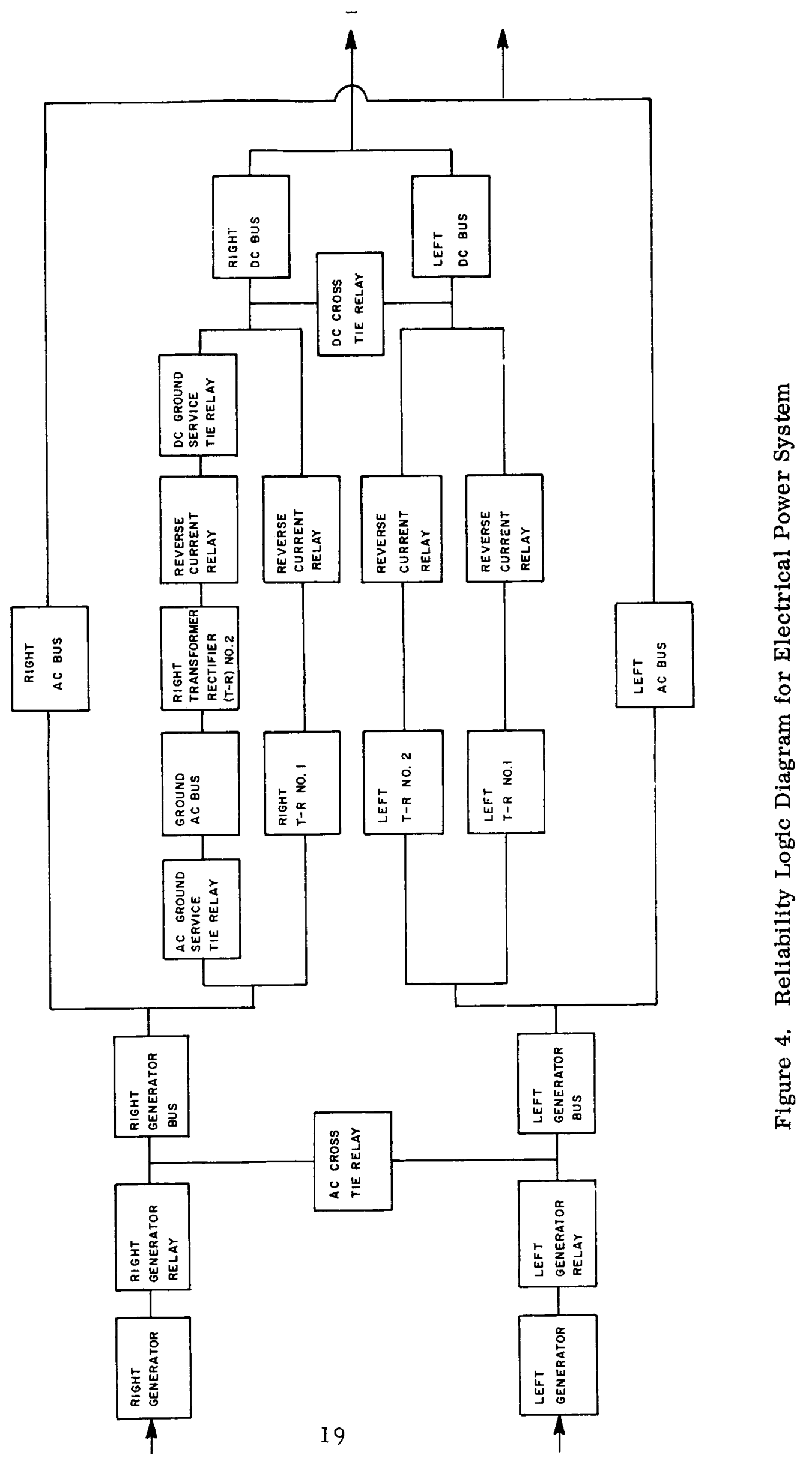


The paths can be traced from left to right by beginning with the source (generators) and ending with the output components (AC and DC buses). While proceeding to trace the paths, blocks are drawn to indicate the components which the logic paths connect, and the components are identified in the blocks. It is also possible to trace the paths from right to left, or from the $\mathrm{AC}$ and $\mathrm{DC}$ buses to the generators. Actually, it may be desirable to trace the paths in both directions to provide a self-checking method.

As an example, consider tracing the paths for making power available to the AC buses. Starting from left to right a block can be constructed in the upper left hand corner to represent the right generator. A path is then drawn from this block to another block which represents the right generator relay. This path is then continued to a block representing the right generator bus and from there to a block representing the right $\mathrm{AC}$ bus. A path for the left hand portion is constructed in a similar manner. A block is constructed in the lower left hand corner to represent the left generator, and the path is continued from left to right, terminating with a block representing the left $\mathrm{AC}$ bus.

After the right and left hand portions are completed, further examination of the diagram reveals a cross-over path to the right of the generator relays and to the left of the generator buses. A block is constructed in the appropriate area which represents the $\mathrm{AC}$ cross tie relay. Paths are then constructed to connect this block to the left and right hand paths. This completes construction of the reliability logic diagram for the AC portion. 
The DC portion is constructed in a similar manner. After the diagram is completed, discussions are held with the system designer to determine the validity of the paths.

Writing the System Reliability Equation

Before proceeding with the analysis of the electrical power distribution system, the method to be used will first be demonstrated on two hypothetical systems. This should make it easier to understand its application later. First consider the simple, two-component system shown in Figure 1-B, Chapter II. The reliability logic diagram of this system depicted a parallel arrangement of component 1 and component 2. As discussed in Chapter II, each component operates successfully or not, and the relationship

$$
R_{i}+Q_{i}=1
$$

is valid where

$R_{i}=$ the reliability (probability of success) of the $i^{\text {th }}$ component and $Q_{i}=$ the unreliability (probability of failure) of the $i^{\text {th }}$ component.

Using this relationship,

$$
\begin{aligned}
& \mathrm{R}_{1}+\mathrm{Q}_{1}=1 \text { and } \\
& \mathrm{R}_{2}+\mathrm{Q}_{2}=1
\end{aligned}
$$

Taking the product of these two equations gives

$$
\left(R_{1}+Q_{1}\right)\left(R_{2}+Q_{2}\right)=(1)(1)=1 .
$$


Expanding the left side of the above equation will produce all possible events for the system. The expansion is

$$
R_{1} R_{2}+R_{1} Q_{2}+Q_{1} R_{2}+Q_{1} Q_{2}=1
$$

Since the system will work properly if either component 1 or component 2 or both work prope:iy, examination of the left side of the equation reveals that the first three terms represent events for which successful system operation will be achieved. Therefore the system reliability $\left(R_{S}\right)$ as a function of the component reliabilities and unreliabilities is

$$
R_{S}=R_{1} R_{2}+R_{1} Q_{2}+Q_{1} R_{2}
$$

Substituting $\left(1-R_{2}\right)$ for $Q_{2}$ and $\left(1-R_{1}\right)$ for $Q_{1}$, the system reliability can be expressed as a function of the component reliabilities. Substituting,

$$
\begin{gathered}
R_{S}=R_{1} R_{2}+R_{1}\left(1-R_{2}\right)+\left(1-R_{1}\right) R_{2} \\
R_{S}=R_{1}+R_{2}-R_{1} R_{2} .
\end{gathered}
$$

This is the same equation that was obtained in Chapter II by direct application of the addition theorem.

The system reliability equation can also be determined from the canonical form presented below. This is merely a scheme to write out all the possible events and show their significance as to success or failure of the system.

The procedure of the technique is first to write down the term which represents success of all the components. Next, the terms are written down which represent the failure of a single component. Then the terms are written 
down to represent the failure of two components. The process is continued until all possible events are represented. The system reliability equation is then written by summing those terms that represent events which result in system success.

$\begin{array}{lll}\text { EVENT } & & \text { SYSTEM CONDITION } \\ \mathrm{R}_{1} \mathrm{R}_{2} & = & \text { Success } \\ \mathrm{R}_{1} \mathrm{Q}_{2} & = & \text { Success } \\ \mathrm{Q}_{1} \mathrm{R}_{2} & = & \text { Success } \\ \mathrm{Q}_{1} \mathrm{Q}_{2} & = & \text { Failure }\end{array}$

Summing the success terms produces the system reliability equation

$$
R_{S}=R_{1} R_{2}+R_{1} Q_{2}+Q_{1} R_{2}
$$

This is the same equation obtained previously.

Now consider a system composed of five components. After being studied, a reliability logic diagram is constructed of the system as shown in Figure 5. This is of a more complex nature than the previous one. System success is achieved if there is an output from component 4 , or component 5 , or both. The system reliability equation is determined by expressing the system events in canonical form, and summing those which represent success.

$\begin{array}{ccc}\text { EVENT } & \text { SYSTEM CONDITION } \\ \mathrm{R}_{1} \mathrm{R}_{2} \mathrm{R}_{3} \mathrm{R}_{4} \mathrm{R}_{5} & = & \text { Success } \\ \mathrm{R}_{1} \mathrm{R}_{2} \mathrm{R}_{3} \mathrm{R}_{4} \mathrm{Q}_{5} & = & \text { Success } \\ \mathrm{R}_{1} \mathrm{R}_{2} \mathrm{R}_{3} \mathrm{Q}_{4} \mathrm{R}_{5} & = & \text { Success }\end{array}$




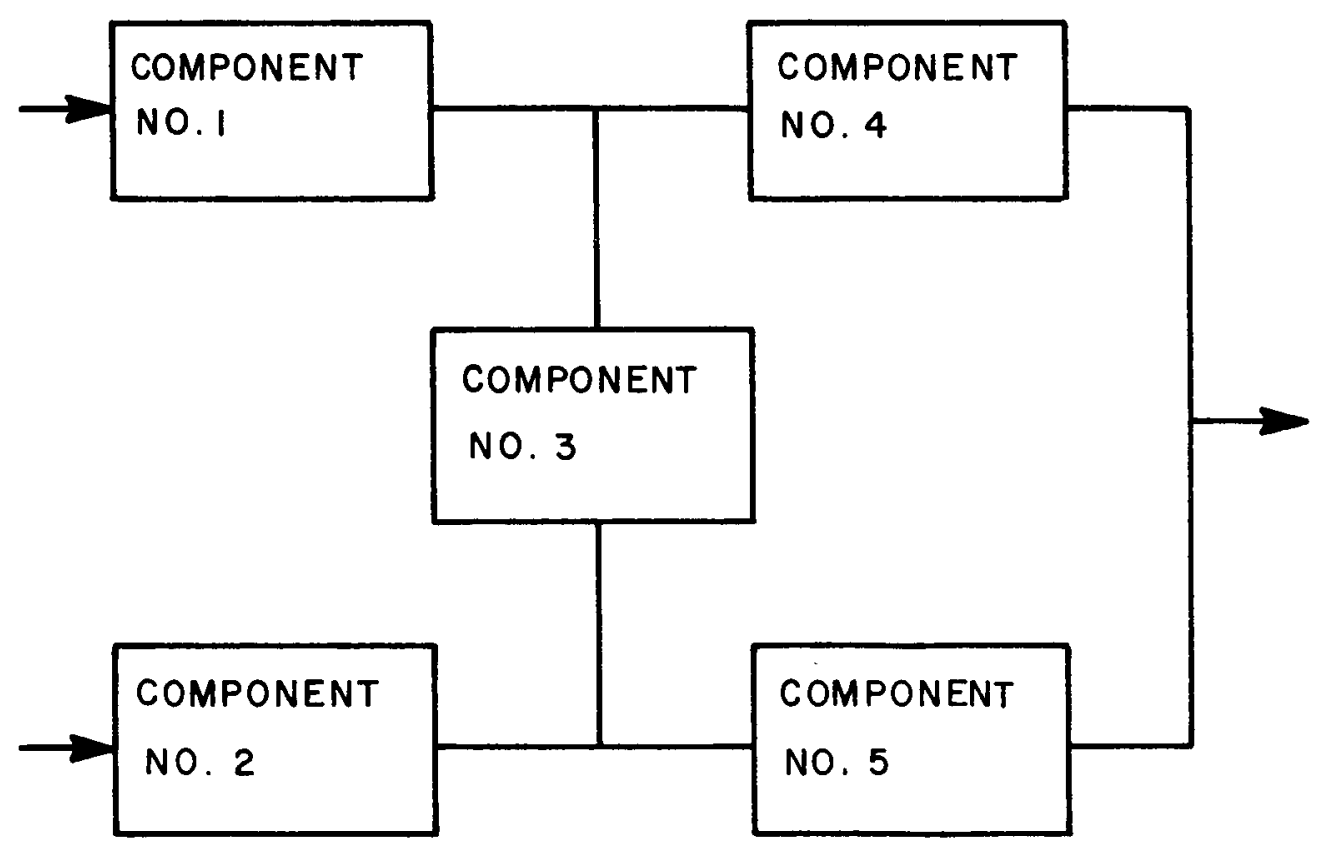

Figure 5. Reliability Logic Diagram for a System of a Complex Nature 


\begin{tabular}{|c|c|c|}
\hline EVENT & & SYSTEM CONDITION \\
\hline $\mathrm{R}_{1} \mathrm{R}_{2} \mathrm{Q}_{3} \mathrm{R}_{4} \mathrm{R}_{5}$ & $=$ & Success \\
\hline$R_{1} Q_{2} R_{3} R_{4} R_{5}$ & $=$ & Success \\
\hline$Q_{1} R_{2} R_{3} R_{4} R_{5}$ & $=$ & Success \\
\hline $\mathrm{R}_{1} \mathrm{R}_{2} \mathrm{R}_{3} \mathrm{Q}_{4} \mathrm{Q}_{5}$ & $=$ & Failure \\
\hline$R_{1} R_{2} Q_{3} R_{4} Q_{5}$ & $=$ & Success \\
\hline$R_{1} Q_{2} R_{3} R_{4} Q_{5}$ & $=$ & Success \\
\hline$Q_{1} R_{2} R_{3} R_{4} Q_{5}$ & $=$ & Success \\
\hline $\mathrm{R}_{1} \mathrm{R}_{2} \mathrm{Q}_{3} \mathrm{Q}_{4} \mathrm{R}_{5}$ & $=$ & Success \\
\hline $\mathrm{R}_{1} \mathrm{Q}_{2} \mathrm{R}_{3} \mathrm{Q}_{4} \mathrm{R}_{5}$ & $=$ & Success \\
\hline $\mathrm{Q}_{1} \mathrm{R}_{2} \mathrm{R}_{3} \mathrm{Q}_{4} \mathrm{R}_{5}$ & $=$ & Success \\
\hline $\mathrm{R}_{1} \mathrm{Q}_{2} \mathrm{Q}_{3} \mathrm{R}_{4} \mathrm{R}_{5}$ & $=$ & Success \\
\hline $\mathrm{Q}_{1} \mathrm{R}_{2} \mathrm{Q}_{3} \mathrm{R}_{4} \mathrm{R}_{5}$ & $=$ & Success \\
\hline$Q_{1} Q_{2} R_{3} R_{4} R_{5}$ & $=$ & Failure \\
\hline$R_{1} R_{2} Q_{3} Q_{4} Q_{5}$ & $=$ & Failure \\
\hline$R_{1} Q_{2} R_{3} Q_{4} Q_{5}$ & $=$ & Failure \\
\hline $\mathrm{Q}_{1} \mathrm{R}_{2} \mathrm{R}_{3} \mathrm{Q}_{4} \mathrm{Q}_{5}$ & $=$ & Failure \\
\hline$R_{1} Q_{2} Q_{3} R_{4} Q_{5}$ & $=$ & Success \\
\hline $\mathrm{Q}_{1} \mathrm{R}_{2} \mathrm{Q}_{3} \mathrm{R}_{4} \mathrm{Q}_{5}$ & $=$ & Failure \\
\hline
\end{tabular}




$\begin{array}{lll}\frac{\text { EVENT }}{\mathrm{Q}_{1} \mathrm{Q}_{2} \mathrm{R}_{3} \mathrm{R}_{4} \mathrm{Q}_{5}} & & \text { SYSTEM CONDITION } \\ \mathrm{R}_{1} \mathrm{Q}_{2} \mathrm{Q}_{3} \mathrm{Q}_{4} \mathrm{R}_{5} & = & \text { Failure } \\ \mathrm{Q}_{1} \mathrm{R}_{2} \mathrm{Q}_{3} \mathrm{Q}_{4} \mathrm{R}_{5} & = & \text { Success } \\ \mathrm{Q}_{1} \mathrm{Q}_{2} \mathrm{R}_{3} \mathrm{Q}_{4} \mathrm{R}_{5} & = & \text { Failure } \\ \mathrm{Q}_{1} \mathrm{Q}_{2} \mathrm{Q}_{3} \mathrm{R}_{4} \mathrm{R}_{5} & = & \text { Failure } \\ \mathrm{R}_{1} \mathrm{Q}_{2} \mathrm{Q}_{3} \mathrm{Q}_{4} \mathrm{Q}_{5} & = & \text { Failure } \\ \mathrm{Q}_{1} \mathrm{R}_{2} \mathrm{Q}_{3} \mathrm{Q}_{4} \mathrm{Q}_{5} & = & \text { Failure } \\ \mathrm{Q}_{1} \mathrm{Q}_{2} \mathrm{R}_{3} \mathrm{Q}_{4} \mathrm{Q}_{5} & = & \text { Failure } \\ \mathrm{Q}_{1} \mathrm{Q}_{2} \mathrm{Q}_{3} \mathrm{R}_{4} \mathrm{Q}_{5} & = & \text { Failure } \\ \mathrm{Q}_{1} \mathrm{Q}_{2} \mathrm{Q}_{3} \mathrm{Q}_{4} \mathrm{R}_{5} & = & \text { Failure } \\ \mathrm{Q}_{1} \mathrm{Q}_{2} \mathrm{Q}_{3} \mathrm{Q}_{4} \mathrm{Q}_{5} & = & \text { Failure }\end{array}$

The system reliability equation can now be determined by summing the terms for those events which represent successful system condition.

$$
\begin{aligned}
R_{s} & =R_{1} R_{2} R_{3} R_{4} R_{5}+R_{1} R_{2} R_{3} R_{4} Q_{5} \\
& +R_{1} R_{2} R_{3} Q_{4} R_{5}+R_{1} R_{2} Q_{3} R_{4} R_{5} \\
& +R_{1} Q_{2} R_{3} R_{4} R_{5}+Q_{1} R_{2} R_{3} R_{4} R_{5} \\
& +R_{1} R_{2} Q_{3} R_{4} Q_{5}+R_{1} Q_{2} R_{3} R_{4} Q_{5} \\
& +Q_{1} R_{2} R_{3} R_{4} Q_{5}+R_{1} R_{2} Q_{3} Q_{4} R_{5}
\end{aligned}
$$




$$
\begin{aligned}
& +R_{1} Q_{2} R_{3} Q_{4} R_{5}+Q_{1} R_{2} R_{3} Q_{4} R_{5} \\
& +R_{1} Q_{2} Q_{3} R_{4} R_{5}+Q_{1} R_{2} Q_{3} R_{4} R_{5} \\
& +R_{1} Q_{2} Q_{3} R_{4} Q_{5}+Q_{1} R_{2} Q_{3} Q_{4} R_{5}
\end{aligned}
$$

By substituting $\left(1-R_{i}\right)$ for $Q_{i}$, the system reliability equation can be simplified. After some tedious reduction processes, the equation becomes

$$
\begin{aligned}
R_{S} & =R_{1} R_{4}+R_{2} R_{5}+R_{1} R_{3} R_{5}+R_{2} R_{3} R_{4} \\
& -R_{1} R_{2} R_{3} R_{4}-R_{1} R_{2} R_{3} R_{5}-R_{1} R_{2} R_{4} R_{5} \\
& -R_{1} R_{3} R_{4} R_{5}-R_{2} R_{3} R_{4} R_{5}+2 R_{1} R_{2} R_{3} R_{4} R_{5} .
\end{aligned}
$$

It will be seen later in the section on numerical evaluation that this reduction is not necessary to obtain a numerical answer.

With the knowledge gained from the analysis of the relatively simple complex system, it will now be easier to understand the analysis of the electrical power distribution system. Reference to the reliability logic diagram of the system in Figure 4 indicates that certain portions of the diagram can be reduced by the techniques used on simple systems. For example, the generator and the generator relay can be combined in series for both the left and right portions of the system. In other words, they can be combined by the application of the multiplication theorem.

In the right hand portion, the $\mathrm{AC}$ ground service tie relay, the ground AC bus, the right transformer rectifier (T-R) No. 2, the reverse current relay, and the DC ground service tie relay can also be combined in series into a single component. The right T-R No. 1 and the reverse current relay can 
be combined in series into a single component. After this reduction, the latter is seen to be in parallel with the former, and they can be reduced to a single component by applying the addition theorem. A similar reduction can be made in the left hand portion of the system.

After the techniques used on simple systems have been applied as extensively as possible, a simplified reliability logic diagram can be constructed as shown in Figure 6. Examination of this diagram reveals that the desired event discussed previously is achieved if there is an output from component 8 or 10 or both and from component 11 or 12 or both. The equation for this system's reliability can also be determined by expressing the possible system events in canonical form, and summing those which represent success. However, these processes become prohibitive for a system with this many components. When this is the case, and the component probabilities of failure are small, it is a good approximation simply to determine the numerical value of the first few success terms and sum them to obtain the system reliability estimate. In view of this, the construction of the canonical scheme for the electrical power system will be delayed until the next section on numerical evaluation.

\section{$\underline{\text { Numerical Evaluation }}$}

For a complex system, the reliability can be estimated by compiling a list of the success terms from the canonical scheme, numerically evaluating them, and obtaining the sum of these numerical values. The estimate can also 


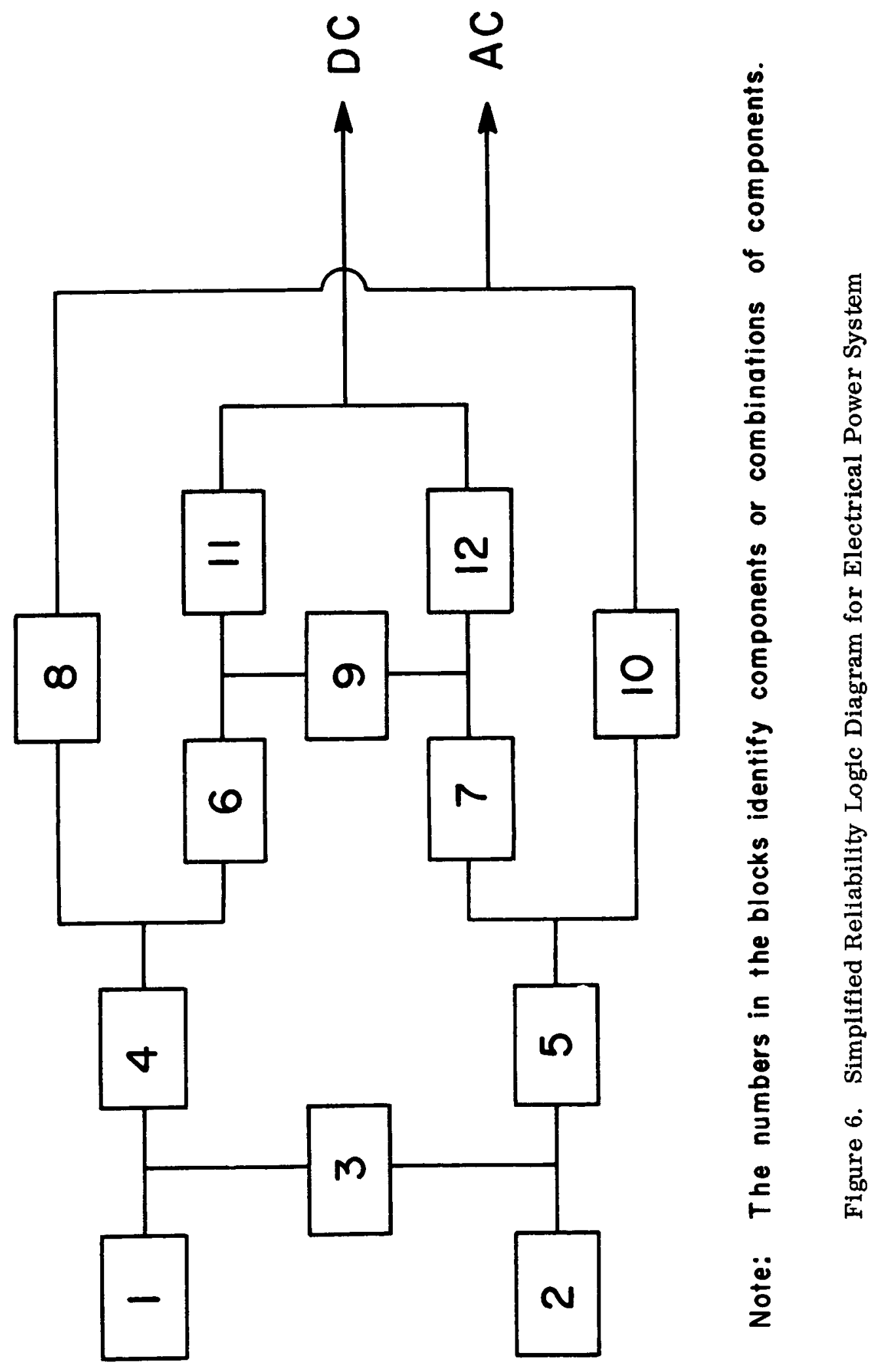


be obtained from the reliability equation after it has been determined by simplifying the sum of the success terms. This can be done quite readily for the system of five components, but as discussed earlier, obtaining the complete expansion for the electrical power system to determine the complete system equation is far too cumbersome. If the component probabilities of failure are small, a good approximation can be obtained from the first few terms as previously discussed.

Both ways will be illustrated using the hypothetical system shown in Figure 5. First consider the method of numerically evaluating the success terms as they appear in the canonical scheme. For convenience of illustration, assume each component has a reliability of 0.90000 (hopefully, much higher in an actual system) and thus an unreliability of 0.10000 .

SUCCESS TERM

$\mathrm{R}_{1} \mathrm{R}_{2} \mathrm{R}_{3} \mathrm{R}_{4} \mathrm{R}_{5}$

$$
\mathrm{R}_{1} \mathrm{R}_{2} \mathrm{R}_{3} \mathrm{R}_{4} \mathrm{Q}_{5}
$$$$
R_{1} R_{2} R_{3} Q_{4} R_{5}
$$$$
\mathrm{R}_{1} \mathrm{R}_{2} \mathrm{Q}_{3} \mathrm{R}_{4} \mathrm{R}_{5}
$$$$
\mathrm{R}_{1} \mathrm{Q}_{2} \mathrm{R}_{3} \mathrm{R}_{4} \mathrm{R}_{5}
$$$$
\mathrm{Q}_{1} \mathrm{R}_{2} \mathrm{R}_{3} \mathrm{R}_{4} \mathrm{R}_{5}
$$$$
\mathrm{R}_{1} \mathrm{R}_{2} \mathrm{Q}_{3} \mathrm{R}_{4} \mathrm{Q}_{5}
$$$$
\mathrm{R}_{1} \mathrm{Q}_{2} \mathrm{R}_{3} \mathrm{R}_{4} \mathrm{Q}_{5}
$$

$=$$$
=
$$$$
=
$$$$
=
$$$$
=
$$$$
=
$$

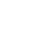$$
=
$$$$
=
$$

NUMERICAL EVALUATION

0.59049

0.06561

0.06561

0. 06561

0. 06561

0.06561

0.00729

0.00729 
SUCCESS TERM

\begin{tabular}{|c|c|c|}
\hline $\mathrm{Q}_{1} \mathrm{R}_{2} \mathrm{R}_{3} \mathrm{R}_{4} \mathrm{Q}_{5}$ & $=$ & 0.00729 \\
\hline $\mathrm{R}_{1} \mathrm{R}_{2} \mathrm{Q}_{3} \mathrm{Q}_{4} \mathrm{R}_{5}$ & $=$ & 0.00729 \\
\hline $\mathrm{R}_{1} \mathrm{Q}_{2} \mathrm{R}_{3} \mathrm{Q}_{4} \mathrm{R}_{5}$ & $=$ & 0.00729 \\
\hline $\mathrm{Q}_{1} \mathrm{R}_{2} \mathrm{R}_{3} \mathrm{Q}_{4} \mathrm{R}_{5}$ & $=$ & 0.00279 \\
\hline $\mathrm{R}_{1} \mathrm{Q}_{2} \mathrm{Q}_{3} \mathrm{R}_{4} \mathrm{R}_{5}$ & $=$ & 0.00729 \\
\hline $\mathrm{Q}_{1} \mathrm{R}_{2} \mathrm{Q}_{3} \mathrm{R}_{4} \mathrm{R}_{5}$ & $=$ & 0.00729 \\
\hline $\mathrm{R}_{1} \mathrm{Q}_{2} \mathrm{Q}_{3} \mathrm{R}_{4} \mathrm{Q}_{5}$ & $=$ & 0.00081 \\
\hline $\mathrm{Q}_{1} \mathrm{R}_{2} \mathrm{Q}_{3} \mathrm{Q}_{4} \mathrm{R}_{5}$ & $=$ & 0.00081 \\
\hline$R_{s}$ & $=$ & 0.97848 \\
\hline
\end{tabular}

NUMERICAL EVALUATION

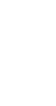

.


success, and F will denote failure. For convenience of illustration, reliabilities for the components as shown in Figure 6 will be assumed to be 0.999000 . Thus the component unreliabilities are $0.001000\left(1 \times 10^{-3}\right)$.

From the binomial expansion, the term indicating three failures is $220 R^{9} Q^{3}$. Since $Q=1 \times 10^{-3}, Q^{3}=\left(1 \times 10^{-3}\right)^{3}=1 \times 10^{-9}$. Now $R$ is less than one, so this would represent a sum total of less than $220 \times 10^{-9}$. Since a portion of this sum represents fallure, terms involving three $Q$ 's would not make any significant contribution. Terms involving higher orders of $\mathrm{Q}$ would decrease correspondingly. Therefore, it is necessary only to list and evaluate those success terms involving zero, one, or two Q's. For those terms representing failure, the word "none" will appear under the numerical value column.

EVENT

$R_{1} R_{2} R_{3} R_{4} R_{5} R_{6} R_{7} R_{8} R_{9} R_{10} R_{11} R_{12}$

$\mathrm{R}_{1} \mathrm{R}_{2} \mathrm{R}_{3} \mathrm{R}_{4} \mathrm{R}_{5} \mathrm{R}_{6} \mathrm{R}_{7} \mathrm{R}_{8} \mathrm{R}_{9} \mathrm{R}_{10} \mathrm{R}_{11} \mathrm{Q}_{12}$

$R_{1} R_{2} R_{3} R_{4} R_{5} R_{6} R_{7} R_{8} R_{9} R_{10} Q_{11} R_{12}$

$R_{1} R_{2} R_{3} R_{4} R_{5} R_{6} R_{7} R_{8} R_{9} Q_{10} R_{11} R_{12}$

$\mathrm{R}_{1} \mathrm{R}_{2} \mathrm{R}_{3} \mathrm{R}_{4} \mathrm{R}_{5} \mathrm{R}_{6} \mathrm{R}_{7} \mathrm{R}_{8} \mathrm{Q}_{9} \mathrm{R}_{10} \mathrm{R}_{11} \mathrm{R}_{12}$

$R_{1} R_{2} R_{3} R_{4} R_{5} R_{6} R_{7} Q_{8} R_{9} R_{10} R_{11} R_{12}$

$R_{1} R_{2} R_{3} R_{4} R_{5} R_{6} Q_{7} R_{8} R_{9} R_{10} R_{11} R_{12}$

$R_{1} R_{2} R_{3} R_{4} R_{5} Q_{6} R_{7} R_{8} R_{9} R_{10} R_{11} R_{12}$

$R_{1} R_{2} R_{3} R_{4} Q_{5} R_{6} R_{7} R_{8} R_{9} R_{10} R_{11} R_{12}$

$\mathrm{R}_{1} \mathrm{R}_{2} \mathrm{R}_{3} \mathrm{Q}_{4} \mathrm{R}_{5} \mathrm{R}_{6} \mathrm{R}_{7} \mathrm{R}_{8} \mathrm{R}_{9} \mathrm{R}_{10} \mathrm{R}_{11} \mathrm{R}_{12}$
SYSTEM

CONDITION

$=\mathrm{S}=$

$=\mathrm{S}=$

$=\mathrm{S}=$

$=\mathrm{S}=$

$=\mathrm{S}=$

$=\mathrm{S}=$

$=\mathrm{S}=$

$=\mathrm{S}=$

$=\mathrm{S} . \quad=$

$=\mathrm{S}=$
NUMERICAL

VALUE

0.98806578

0.00098905

0.00098905

0.00098905

0.00098905

0.00098905

0.00098905

0. 00098905

0.00098905

0.00098905 
$\underline{\text { EVENT }}$

\begin{tabular}{|c|c|c|c|c|}
\hline$R_{1} R_{2} Q_{3} R_{4} R_{5} R_{6} R_{7} R_{8} R_{9} R_{10} R_{11} R_{12}$ & $=$ & $\mathbf{S}$ & $=$ & 0.00098905 \\
\hline$R_{1} Q_{2} R_{3} R_{4} R_{5} R_{6} R_{7} R_{8} R_{9} R_{10} R_{11} R_{12}$ & $=$ & $\mathbf{S}$ & $=$ & 0.00098905 \\
\hline$Q_{1} R_{2} R_{3} R_{4} R_{5} R_{6} R_{7} R_{8} R_{9} R_{10} R_{11} R_{12}$ & $=$ & $\mathbf{S}$ & $=$ & 0.00098905 \\
\hline
\end{tabular}

In the events that are iterated below, the appropriate $\mathrm{R}$ belongs to a space if that space is void of a symbol.

\begin{tabular}{|c|c|c|c|c|c|}
\hline \multicolumn{2}{|c|}{$R_{1} R_{2} R_{3} R_{4} R_{5} R_{6} R_{7} R_{8} R_{9} R_{10} Q_{11} Q_{12}$} & $=$ & $\mathrm{F}$ & $=$ & None \\
\hline$Q_{10}$ & $10 \quad Q_{12}$ & $=$ & $\mathbf{S}$ & $=$ & .00000099 \\
\hline $\mathrm{Q}_{9}$ & $Q_{12}$ & $=$ & $\mathbf{S}$ & $=$ & .00000099 \\
\hline $\mathrm{Q}_{8}$ & $\mathrm{Q}_{12}$ & $=$ & $\mathbf{S}$ & $=$ & .00000099 \\
\hline $\mathrm{Q}_{7}$ & $Q_{12}$ & $=$ & $\mathbf{S}$ & $=$ & .00000099 \\
\hline $\mathrm{Q}_{6}$ & $\mathrm{Q}_{12}$ & $=$ & $\mathbf{S}$ & $=$ & .00000099 \\
\hline$Q_{5}$ & $\mathrm{Q}_{12}$ & $=$ & $\mathbf{S}$ & $=$ & .00000099 \\
\hline $\mathrm{Q}_{4}$ & $\mathrm{Q}_{12}$ & $=$ & $\mathbf{S}$ & $=$ & .00000099 \\
\hline $\mathrm{Q}_{3}$ & $\mathrm{Q}_{12}$ & $=$ & $\mathbf{S}$ & $=$ & .00000099 \\
\hline $\mathrm{Q}_{2}$ & $\mathrm{Q}_{12}$ & $=$ & $\mathbf{S}$ & $=$ & .00000099 \\
\hline$Q_{1}$ & $\mathrm{Q}_{12}$ & $=$ & $\mathbf{S}$ & $=$ & .00000099 \\
\hline \multicolumn{2}{|c|}{$R_{1} R_{2} R_{3} R_{4} R_{5} R_{6} R_{7} R_{8} R_{9} Q_{10} Q_{11} Q_{12}$} & $=$ & $\mathbf{S}$ & $=$ & .00000099 \\
\hline $\mathrm{Q}_{9}$ & $\mathrm{Q}_{11}$ & $=$ & $\mathbf{S}$ & $=$ & .00000099 \\
\hline $\mathrm{Q}_{8}$ & $\mathrm{Q}_{11}$ & $=$ & S & $=$ & .00000099 \\
\hline$Q_{7}$ & $\mathrm{Q}_{11}$ & $=$ & $\mathbf{S}$ & $=$ & .00000099 \\
\hline $\mathrm{Q}_{6}$ & $\mathrm{Q}_{11}$ & $=$ & $\mathbf{S}$ & $=$ & .00000099 \\
\hline
\end{tabular}


EVENT

\begin{tabular}{|c|c|c|c|c|c|}
\hline \multicolumn{2}{|c|}{$R_{1} R_{2} R_{3} R_{4} Q_{5} R_{6} R_{7} R_{8} R_{9} R_{1} Q_{11} R_{12}$} & $=$ & $\mathbf{S}$ & $=$ & .00000099 \\
\hline $\mathrm{Q}_{4}$ & $Q_{11}$ & $=$ & $\mathbf{S}$ & $=$ & .00000099 \\
\hline $\mathrm{Q}_{3}$ & $Q_{11}$ & $=$ & $\mathbf{S}$ & $=$ & .00000099 \\
\hline $\mathrm{Q}_{2}$ & $Q_{11}$ & $=$ & $\mathbf{S}$ & $=$ & .00000099 \\
\hline $\mathrm{Q}_{1}$ & $\mathrm{Q}_{11}$ & $=$ & $\mathbf{S}$ & $=$ & .00000099 \\
\hline \multicolumn{2}{|c|}{$R_{1} R_{2} R_{3} R_{4} R_{5} R_{6} R_{7} R_{8} Q_{9} Q_{10} R_{11} R_{12}$} & $=$ & $\mathbf{S}$ & $=$ & .00000099 \\
\hline & $Q_{8} \quad Q_{10}$ & $=$ & $\mathrm{F}$ & $=$ & None \\
\hline $\mathrm{Q}_{7}$ & $Q_{10}$ & $=$ & $\mathbf{S}$ & $=$ & .00000099 \\
\hline$Q_{6}$ & $Q_{10}$ & $=$ & $\mathbf{S}$ & $=$ & .00000099 \\
\hline$Q_{5}$ & $Q_{10}$ & $=$ & $\mathbf{S}$ & $=$ & .00000099 \\
\hline $\mathrm{Q}_{4}$ & $\mathrm{Q}_{10}$ & $=$ & $\mathrm{F}$ & $=$ & None \\
\hline$Q_{3}$ & $\mathrm{Q}_{10}$ & $=$ & $\mathrm{S}$ & $=$ & .00000099 \\
\hline $\mathrm{Q}_{2}$ & $Q_{10}$ & $=$ & $\mathrm{S}$ & $=$ & .00000099 \\
\hline$Q_{1}$ & $Q_{10}$ & $=$ & $\mathbf{S}$ & $=$ & .00000099 \\
\hline \multicolumn{2}{|c|}{$R_{1} R_{2} R_{3} R_{4} R_{5} R_{6} R_{7} Q_{8} Q_{9} R_{10} R_{11} R_{12}$} & $=$ & $\mathbf{S}$ & $=$ & .00000099 \\
\hline$Q_{\eta}$ & $Q_{9}$ & $=$ & $\mathrm{S}$ & $=$ & .00000099 \\
\hline$Q_{6}$ & $Q_{9}$ & $=$ & $\mathrm{S}$ & $=$ & .00000099 \\
\hline$Q_{5}$ & $Q_{9}$ & $=$ & $\mathbf{S}$ & $=$ & .00000099 \\
\hline$Q_{4}$ & $\mathrm{Q}_{9}$ & $=$ & $\mathrm{S}$ & $=$ & .00000099 \\
\hline $\mathrm{Q}_{3}$ & $\mathrm{Q}_{9}$ & $=$ & $\mathbf{S}$ & $=$ & .00000099 \\
\hline
\end{tabular}

VALUE

CONDITION

NUMERICAL

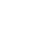




\section{EVENT}

$R_{1} Q_{2} R_{3} R_{4} R_{5} R_{6} R_{7} Q_{8} Q_{9} R_{10} R_{11} R_{12}$

$\mathrm{Q}_{1}$

$Q_{9}$

$R_{1} R_{2} R_{3} R_{4} R_{5} R_{6} Q_{7} Q_{8} R_{9} R_{10} R_{11} R_{12}$

$\mathrm{Q}_{6} \quad \mathrm{Q}_{8}$

$\mathrm{Q}_{5} \quad \mathrm{Q}_{8}$

$Q_{4}$

$Q_{8}$

$Q_{3}$

$Q_{8}$

$Q_{2}$

$Q_{8}$

$Q_{1}$

$Q_{8}$

$R_{1} R_{2} R_{3} R_{4} R_{5} Q_{6} Q_{7} R_{8} R_{9} R_{10} R_{11} R_{12}$

$\begin{array}{ll}\mathrm{Q}_{5} & \mathrm{Q}_{7}\end{array}$

$Q_{4} \quad Q_{7}$

$Q_{3}$

$Q_{7}$

$\mathrm{Q}_{2}$

$Q_{1}$

$Q_{7}$

$Q_{7}$

$R_{1} R_{2} R_{3} R_{4} Q_{5} Q_{6} R_{7} R_{8} R_{9} R_{10} R_{11} R_{12}$

$\begin{array}{ll}Q_{4} & Q_{6}\end{array}$

$\mathrm{Q}_{3} \quad \mathrm{Q}_{6}$

$\mathrm{Q}_{2}$

$\mathrm{Q}_{6}$

$Q_{1}$

$Q_{6}$
SYSTEM

CONDITION

$=\mathrm{S}=$

$=\mathrm{S}=$

$=\mathrm{S}$

$=$

$=$

$=$

$=$

$=\mathbf{S}$

$=\mathrm{S}$

$=\mathrm{S}$

$\mathbf{S}$

$=\mathbf{F}=$

$=\mathrm{S}=$

$=F=$

$=\mathrm{S}=$

$=\mathrm{S}=$

$=\mathrm{S}=$

$=$

$=$

$=$

$=$
NUMERICAL

VALUE

.00000099

.00000099

.00000099

00000099

None

.00000099

.00000099

.00000099

.00000099

None

.00000099

None

.00000099

.00000099

00000099

None

.00000099

.00000099

.00000099

.00000099 


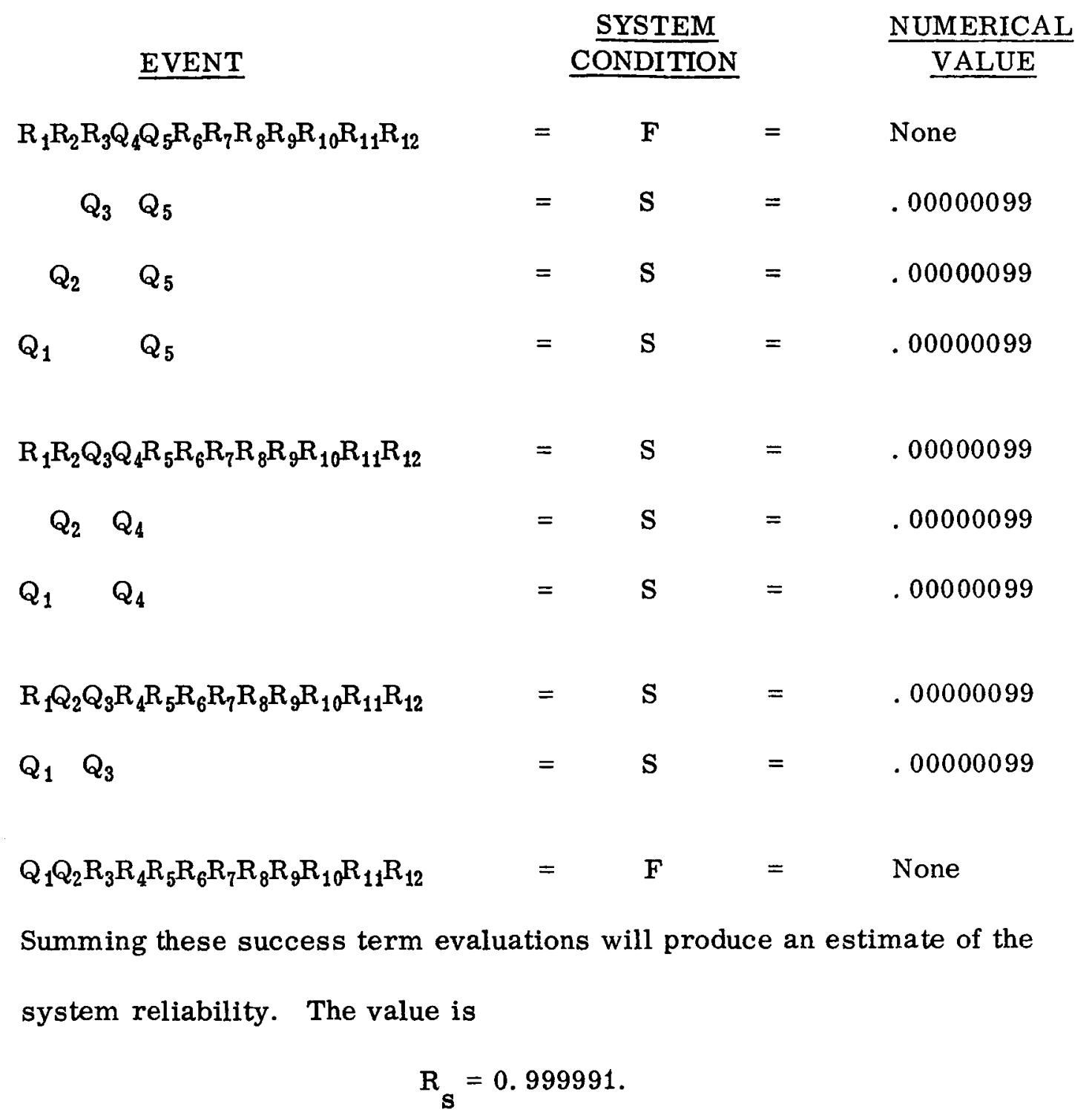




\section{CHAPTER IV. COMPONENT RELIABILITIES}

\section{Component Reliability Functions}

Before proceeding further, the determination of the reliabilities of the components that make up a system should be discussed. This will not be an all inclusive discussion, as component reliability functions are treated in several books such as the one by Lloyd and Lipow. ${ }^{1}$ Component reliability functions have been derived from the specific applications of functions that have existed for many years.

The reliability function can be computed from the mutually exclusive relationship

Thus

$$
R(t)+Q(t)=1
$$

$$
R(t)=1-Q(t), \text { where }
$$

$R(t)=$ reliability of the component as a function of time (or some other variable) and one or more parameters, and $\mathrm{Q}(\mathrm{t})=$ unreliability of the component as a function of time (or some other variable) and one or more parameters.

The component unreliability function can be defined in terms of a failure distribution function (cumulative probability) or in terms of a failure frequency

${ }^{1}$ D. K. Lloyd and M. Lipow, Reliability: Management, Methods, and Mathematics, Prentice-Hall, Inc. , Englewood Cliffs, New Jersey, 1962, pp. 112-156. 
function (probability density function). These functions can be discrete or continuous. Many of these functions exist, but only a few will be discussed.

For a continuous function, the unreliability distribution function is

$$
Q(t)=\operatorname{Pr}(T \leq t) ; 0<t<\infty
$$

This equation states that the unreliability, as a function of the variable time, is equal to the probability that the time of fallure, $T$, is less than or equal to the time, $t$. In other words, it is the probability that the component has failed in the time interval 0 to $t$.

If $f(t)$ is the time derivation of $Q(t)$ then

$$
f(t) d t=\operatorname{Pr}(t \leq T \leq t+d t) .
$$

In this equation, $f(t)$ is the failure frequency function. The left hand side of the equation represents the frequency with which the component, beginning to operate at $t=0$, will fail in the interval $t$ to $t+d t$.

From the proceeding discussions, it can be seen that

$$
Q(t)=\int_{0}^{t} f(t) d t
$$

Using the basic concept of a frequency function, ${ }^{2}$ the component reliability function is determined to be

$$
\begin{gathered}
R(t)=1-Q(t)=1-\int_{0}^{t} f(t) d t, \text { or } \\
R(t)=\int_{t}^{\infty} f(t) d t .
\end{gathered}
$$

This follows from the relationship

$$
\int_{0}^{t} f(t) d t+\int_{t}^{\infty} f(t) d t=1
$$

${ }^{2}$ P. G. Hoel, Introduction to Mathematical Statistics, John Wiley \& Sons, New York, N. Y. , 1962, p. 35. 
For a discrete function, the failure frequency function, $f(x)$, is a function that gives the probability that the random variable $x$ will assume any particular value in its range. Thus

$$
\begin{gathered}
Q(x)=\sum_{x=0}^{a-1} f(x)=\operatorname{Pr}(0 \leq x \leq a-1), \text { and } \\
R(x)=\sum_{x=a}^{n} f(x), \text { since } \\
\sum_{x=0}^{a-1} f(x)+\sum_{x=a}^{n} f(x)=1
\end{gathered}
$$

The Normal Function

The normal function is used as an approximating function to compute the reliability of a component when the component tends to have wearout characteristics. The fallure frequency function for the normal function is

$$
f(t)=\frac{1}{\sigma \sqrt{2 \pi}} e^{\frac{-(t-M)^{2}}{2 \sigma^{2}}}, \text { where }
$$

$t=$ the age of the component,

$\mathrm{M}=$ the mean wearout life, and

$\sigma=$ the standard deviation of the lifetimes from the mean M.

If the component starts operating at $t=0$, the unreliability of the component for a period of operation to time $\mathrm{T}$ is

$$
Q(T)=\int_{0}^{T} f(t) d t=\int_{0}^{T} \frac{1}{\sigma \sqrt{2 \pi}} e^{\frac{-(t-M)}{2 \sigma^{2}}} d t .
$$


Since the normal function is defined from $-\infty$ to $+\infty$, the lower limit should be $-\infty$. However, when the transformation of variables is made, the lower limit should be sufficiently small to indicate a negligible error when the evaluation is made using the standard normal tables. The component reliability function is

$$
\mathbf{R}(\mathbf{T})=\int_{\mathrm{T}}^{\infty} \frac{1}{\sigma \sqrt{2 \pi}} \mathrm{e}^{\frac{-(t-M)^{2}}{2 \sigma^{2}}} \mathrm{dt}
$$

In the above equations, the parameters $M$ and $\sigma$ actually represent sample estimates rather than the true population parameters.

When the component reliabilities are computed, it is desirable to have the estimated parameters of the functions adjusted to a specified confidence level. In the normal case, the mean wearout life is adjusted to a lower level one-sided confidence limit. If $\gamma$ is the confidence level, the desired equation is

$$
\operatorname{Pr}\left(\hat{\mathbf{M}}-\mathrm{K}_{\alpha} \frac{\sigma}{\sqrt{\mathrm{n}}} \leqq \mathrm{M}\right)=\gamma=0.90
$$

for example, where $\hat{M}$ is the estimated mean,

$\mathrm{K}$ is the number of standard deviations from the mean and is a percentage point 
on the abscissa of the standardized normal curve for a certain area under the curve, and the subscript

$$
\alpha=1-\gamma^{3}
$$

The equation

$$
\operatorname{Pr}\left(\hat{\mathrm{M}}-\mathrm{K}_{\alpha} \frac{\sigma}{\sqrt{\mathrm{n}}} \leq \mathrm{M}\right)=\gamma
$$

states that the probability is equal to $\gamma$ and that the true mean wearout life is greater than or equal to

$$
\left(\hat{M}-K_{\alpha} \frac{\sigma}{\sqrt{n}}\right) \text {. }
$$

Thus

$$
\mathrm{M}_{\mathrm{L}}=\hat{\mathbf{M}}-\mathrm{K}_{\alpha} \frac{\sigma}{\sqrt{\mathrm{n}}}
$$

is the value used in the component reliability function for the mean wearout life.

As an example, assume the following data were available for a component:

$$
\begin{array}{ll}
\hat{\mathbf{M}}=1000 \text { hours } & \mathrm{n}=36 \\
\sigma \cong \mathrm{s}=196 \text { hours } & \gamma=0.90 \text { (confidence level) } .
\end{array}
$$

${ }^{3}$ B. W. Lindgren and G. W. McElrath, Introduction to Probability and Statistics, The Macmillan Company, New York, N. Y., 1959, pp. 165-167. 
The mean wearout life adjusted to the lower limit would be

$$
M_{L}=1000-K_{0.10} \frac{196}{\sqrt{36}}=1000-1.28 \frac{(196)}{6}
$$

$M_{L}=967,3$ hours.

This would be the value used in the reliability function.

With an operating time of 500 hours, the reliability would be computed

as

$$
R(500)=\int_{500}^{\infty} f(t) d t .
$$

Using the standard transformation,

$$
\mathrm{z}=\frac{\mathrm{t}-\mathrm{M}}{\sigma}=\frac{500-967.3}{196}=-\frac{467.3}{196}=-2.38 .
$$

The area under the curve corresponding to this value gives a reliability of $\mathrm{R}=0.9913$.

The Binomial Function

The binomial function can be used to compute the reliability of a component when the component operation consists of a number of trials for a given period of operation. It is a discrete function and its failure frequency function is

$$
f(x)=\frac{n !}{x !(n-x) !} R^{x}(1-R)^{n-x}
$$

$\mathrm{n}=$ number of items tested or subjected to operation,

$R$ = probability of successful operation on any one trial, and 
$x=$ number of successful trials out of the total number $n .{ }^{4}$

The component reliability function is given by

$$
R(s)=\sum_{x=s}^{n} \frac{n !}{x !(n-x) !} R^{x}(1-R)^{n-x}
$$

where the component must operate at least an $s$ number of times. In this equation, $n$ may very well be equal to $s$. In actual practice, $R$ in the above equation represents an estimate which has been adjusted to a lower one-sided confidence limit.

The lower one-sided confidence limit estimate is computed from the equation

$$
\sum_{x=s}^{n} \frac{n !}{x !(n-x) !} \quad R_{L}^{x}\left(1-R_{L}\right)^{n-x}=1-\gamma, \text { where }
$$

$\mathrm{n}=$ number of trials from which $\mathrm{R}$ is estimated, and

$R_{L}=$ reliability for the one-sided lower confidence limit.

For a given confidence level, $\gamma$, the equation can be solved for $R_{L}$. This provides a $100 \gamma$ percent confidence statement that the true reliability, $R$, is greater than or equal to the lower one-sided confidence limit $R_{L}$. This equation can be solved by trial and error or by the use of established tables. ${ }^{5}$

${ }^{4}$ P. G. Hoel, Introduction to Mathematical Statistics, John Wiley \& Sons, New York, N. Y., 1962, pp. 86, 239.

${ }^{5}$ J. R. Cooke, M. T. Lee, and J. P. Vanderbeck, Binomial Reliability Table, U. S. Naval Ordnance Test Station, China Lake, Calif., January 1964. 
As an example, assume that a component had been subjected to 500 trials and was successful 499 times. For a given confidence level of $\gamma=0.90$, the established tables give a lower one-sided confidence limit of $R_{L}=0.99224$.

This is the value used in the component reliability function. If the component had to operate successfully for one trial during a given period of operation, its reliability would be computed as

$$
\begin{aligned}
& R(1)=\sum_{x=1}^{1} \frac{1 !}{1 ! 0 !}(0.99224)^{1}(1-0.99224)^{0} \\
& R(1)=0.99224 .
\end{aligned}
$$

The Exponential Function

The exponential function is used as an approximating function to compute the reliability of a component when the component is subjected to failures that occur at random intervals. The failure frequency function for the exponential function is

$$
f(t)=\lambda e^{-\lambda t} \text {, where }
$$

$t=$ operating time period, and $\lambda=$ average failure rate (assumed to be a constant).

If the component starts operating at $t=0$, the unreliability of the component for a period of operation to time $t$ is

$$
\begin{aligned}
& Q(t)=\int_{0}^{t} f(t) d t=\int_{0}^{t} \lambda e^{-\lambda t} d t \\
& Q(t)=1-e^{-\lambda t} .
\end{aligned}
$$


The reliability of the component is

$$
\begin{aligned}
& R(t)=\int_{t}^{\infty} f(t) d t=\int_{t}^{\infty} \lambda e^{-\lambda t} d t \\
& R(t)=e^{-\lambda t} .
\end{aligned}
$$

The reliability function for the exponential situation can be derived as a special case of the generalized Poisson Law

$$
P_{n}(t)=\frac{(\lambda t)^{n}}{n !} e^{-\lambda t}
$$

where $P_{n}(t)$ is the probability of exactly $n$ failures during the time interval 0 to t. ${ }^{6}$ For a given component, the probability of having zero failures for that particular component is

$$
\begin{aligned}
& R(t)=P_{0}(t)=\frac{(\lambda t)^{0}}{0 !} e^{-\lambda t}=e^{-\lambda t} \\
& R(t)=e^{-\lambda t} .
\end{aligned}
$$

The lower one-sided confidence limit for the exponential case is taken care of by adjusting the mean-time-between failure parameter. The meantime-between failure, denoted by $m$, is given as the reciprocal of the failure rate, or $m=\frac{1}{\lambda}$. It has been shown that the ratio $2 r \frac{m}{m}$ is a random variable which is distributed as chi-square $\left(\chi^{2}\right)$ with $2 \mathrm{r}$ degrees of freedom

${ }^{6}$ I. S. Sokolnikoff and R. M. Redheffer, Mathematics of Physics and Modern Engineering, McGraw-Hill Book Co. , Inc., New York, N. Y. , pp. 654-657. 
where $\mathrm{r}$ is the number of failures. ${ }^{7}$ The estimate $\hat{\mathrm{m}}$ is obtained by dividing the total test time ( $T$ ) by the number of failures. The symbol $\mathrm{m}$ represents the true population parameter. The confidence limit equation is

$$
\operatorname{Pr}\left(\frac{2 \mathrm{rm}}{\mathrm{m}} \leq \chi_{\alpha ; 2 \mathrm{r}}^{2}\right)=1-\alpha=\gamma
$$

This equation states that there is a probability of $\gamma$ that the value of the ratio $\frac{2 \mathrm{rm}}{\mathrm{m}}$ will be less than or equal to the indicated chi-square percentage point.

By rearrangement, the equation may be written as

$$
\operatorname{Pr}\left(\frac{2 \mathrm{rm}}{\chi_{\alpha ; 2 r}^{2}} \leq \mathrm{m}\right)=1-\alpha=\gamma
$$

Thus the lower one-sided confidence limit is

$$
\mathrm{C}_{\mathrm{L}}=\frac{2 \mathrm{rm}}{\chi_{\alpha ; 2 \mathrm{r}}^{2}}
$$

The probability is $\gamma$ that the true $m$ will be greater than or equal to this value.

It is this value that is used in the component reliability function.

As an example, suppose that from actual component operating experience an estimate $\hat{\mathrm{m}}$ were determined to be

$$
\hat{\mathrm{m}}=\frac{\mathrm{T}}{\mathrm{r}}=\frac{20,000}{1} \text { hours, where }
$$

$r=1$, the number of failures, and

$\mathrm{T}=$ total test time, 20,000 hours.

For a 90 percent confidence level $(\gamma)$, the lower one-sided confidence limit is

$$
\mathrm{C}_{\mathrm{L}}=\frac{2 \mathrm{rm}}{\chi_{\alpha ; 2 \mathrm{r}}^{2}}=\frac{(2)(1)(20,000)}{\chi_{0.10 ; 2}^{2}}=\frac{40,000}{4.605}
$$

${ }^{7}$ B. Epstein and M. Sobel, "Life Testing," American Statistical Association Journal, Sept. 1953, pp. 486-502. 
$\mathrm{C}_{\mathrm{L}}=8,700$ hours.

Using this value and a one-hour operating time, the component reliability equation gives

$$
\begin{aligned}
& R(t)=e^{-\lambda t}=e^{-\frac{1}{m} t} \\
& R(1)=e^{-0.000115} \\
& R(1)=0.999885 .
\end{aligned}
$$

The Weibull Function

The Weibull function is a function which has the capability of theoretically describing many different shapes of failure rate functions. The failure frequency function for the Weibull function is

$$
f(t)=\alpha \lambda t^{\alpha-1} e^{-\lambda t^{\alpha}}, \text { where }
$$

$\alpha>0, \lambda>0$

$\lambda=$ scale parameter, and

$\alpha=$ shape parameter. ${ }^{8}$

If a component has a Weibull failure frequency function, the unreliability of the component for a period of operation from $t=0$ to time $t$ is

$$
\begin{aligned}
& Q(t)=\int_{0}^{t} f(t) d t \\
& Q(t)=1-e^{-\lambda t^{\alpha}}
\end{aligned}
$$

${ }^{8}$ D. K. Lloyd, and M. Lipow, Reliability: Management Methods, and Mathematics, Prentice-Hall, Inc. Englewood Cliffs, New Jersey, 1962, pp. 137-138. 
The reliability of the component for the same operating period would be

$$
R(t)=e^{-\lambda t^{\alpha}}
$$

When the shape parameter, $\alpha$, is equal to one, the exponential function is a special case of the Weibull function. If $\alpha=1$ is substituted into the component reliability function, the result is $R(t)=e^{-\lambda t}$. This is the same equation obtained in the previous section for the exponential function.

\section{Selection of a Function}

When a theoretical probability function is being considered as a model for the actual probability function, the model should be tested to see how well it fits the actual situation. If sufficient data are available to formulate an empirical frequency function, one test that can be used is the chi-square goodness-of-fit test to see how well an assumed theoretical function matches the actual situation. If sufficient data are not available, the function must be selected by using judgement based on past experience and a logical rationale.

The chi-square goodness-of-fit test is performed by evaluating the function

$$
\chi^{2}=\sum_{j=1}^{k} \frac{\left(0_{j}-E_{j}\right)^{2}}{E_{j}} \text {, where }
$$

$0_{\mathrm{j}}=$ observed frequencies,

$E_{j}=$ expected or theoretical frequencies,

$\chi_{\mathrm{d}, \alpha}^{2}=$ critical value,

$d=k-1-h=$ degrees of freedom, 
$\mathrm{k}=$ number of class intervals,

$\mathrm{h}=$ number of population parameters estimated to determine expected

frequencies, and

$\alpha=$ level of significance for the test. ${ }^{9}$

The test is performed by stating a hypothesis that the data come from some theoretical function. If the calculated value of the chi-square is greater than the critical value, the hypothesis is rejected. If the calculated value is less than or equal to the critical value, the hypothesis is not rejected. The latter means that the theoretical function can be used as an approximation to the actual situation.

As an example of how data inputs to determine models are analyzed to establish a reliability function for a component, assume that the data listed below have been collected on a particular component. The data presented represent the time in hours at which a component failed when it started operating at $\mathrm{t}=0$.

Time of failure in hours

500

750

900

1000
4400

4800

5000

5400

${ }^{9}$ M. R. Spiegel, Theory and Problems of Statistics, Schaum

Publishing Co., New York, N. Y., 1961 pp. 201-202. 
Time of failure in hours

1500

1700

1750

2200

2600

2900

3000

3500

3700

3900

4000
5600

6600

7700

8300

8700

9700

10500

11600

11800

12500

13500

$$
\text { Total }=150,000 \text { hours }
$$

If these data are grouped into convenient time intervals and the frequency of failures is plotted against the time intervals, this will provide a rough idea of the form of the failure frequency function. If an equal time interval of 1000 hours is selected and the data plotted on this basis, the form will indicate that a theoretical exponential frequency function might be a good model or reliability function for this component. The chi-square goodness-of-fit test will be applied to this data to see how well the theoretical function fits the actual 
situation. When this test is used in actual practice, a much larger sample is desirable; however, this sample will be sufficient for the purposes of illustration.

The hypothesis here is that the data came from an exponential population. The level of significance $(\alpha)$ is selected as $\alpha=0.20$. This is the probability of rejecting the hypothesis when it is actually true. Before applying the chi-square test, it is necessary to determine the expected or theoretical values for the chosen class intervals. To do this, it is necessary to determine the parameters of the theoretical function which is the exponential in this case. The exponential failure frequency function is given as

$$
f(t)=\lambda e^{-\lambda t}
$$

The only parameter in this function is lambda $(\lambda)$, and it is determined by

$$
\begin{aligned}
& \lambda=\frac{\mathrm{n}}{\mathrm{n}} \text {, where } \\
& \sum_{i=1} t_{i}
\end{aligned}
$$

$\mathrm{n}$ = sample size or the number of components that have failed, and $t_{i}=$ time of failure for the $i^{\text {th }}$ component.

The next step is to set the $\mathrm{k}$ class intervals and to determine the theoretical relative frequencies for each class interval. The theoretical or expected absolute frequencies for each class interval is then determined by multiplying the theoretical relative frequency of each class interval by the value of $n$. The relative frequency for a particular class interval can be determined by setting an upper limit for that class interval, determining the 
cumulative probability for that upper limit, and subtracting the cumulative probability to the upper limit of the next lower class. The results of applying this procedure are shown in Table I.

Table I. Determination of Data for Applying Chi-Square Test

\begin{tabular}{|c|c|c|c|c|}
\hline $\begin{array}{c}\text { Class } \\
\mathbf{j}\end{array}$ & $\begin{array}{l}\text { Upper limit } \\
\text { of class } \\
\text { interval }\end{array}$ & $\begin{array}{l}\text { Theoretical } \\
\text { Cumulative } \\
\text { Probability }\end{array}$ & $\begin{array}{l}\text { Theoretical } \\
\text { Relative } \\
\text { Frequency }\end{array}$ & $\begin{array}{l}\text { Theoretical } \\
\text { Absolute } \\
\text { Frcquency }\end{array}$ \\
\hline 1 & 500 & .10 & .10 & 3. 0 \\
\hline 2 & 1000 & .18 & .08 & 2.4 \\
\hline 3 & 1500 & .26 & .08 & 2.4 \\
\hline 4 & 2000 & .33 & .07 & 2.1 \\
\hline 5 & 2500 & .39 & .06 & 1.8 \\
\hline 6 & 3000 & .45 & .06 & 1.8 \\
\hline 7 & 3500 & .50 & .05 & 1.5 \\
\hline 8 & 4000 & .55 & .05 & 1.5 \\
\hline 9 & 4500 & .59 & .04 & 1.2 \\
\hline 10 & 5000 & .63 & .04 & 1.2 \\
\hline 11 & 5500 & .67 & .04 & 1.2 \\
\hline 12 & 6000 & .70 & .03 & .9 \\
\hline 13 & 6500 & .73 & .03 & .9 \\
\hline 14 & 7000 & .75 & .02 & .6 \\
\hline 15 & 7500 & .78 & .03 & .9 \\
\hline 16 & 8000 & .80 & .02 & .6 \\
\hline 17 & 8500 & .82 & .02 & .6 \\
\hline
\end{tabular}


Table I. --Continued

\begin{tabular}{|c|c|c|c|c|}
\hline $\begin{array}{c}\text { Class } \\
\mathbf{j}\end{array}$ & $\begin{array}{l}\text { Upper limit } \\
\text { of class } \\
\text { interval }\end{array}$ & $\begin{array}{l}\text { Theoretical } \\
\text { Cumulative } \\
\text { Probability }\end{array}$ & $\begin{array}{l}\text { Theoretical } \\
\text { Relative } \\
\text { Frequency }\end{array}$ & $\begin{array}{l}\text { Theoretical } \\
\text { Absolute } \\
\text { Frequency }\end{array}$ \\
\hline 18 & 9000 & .83 & .01 & .3 \\
\hline 19 & 9500 & .85 & .02 & .6 \\
\hline 20 & 10000 & .86 & .01 & .3 \\
\hline 21 & 11000 & .89 & .03 & .9 \\
\hline 22 & 12000 & .91 & .02 & .6 \\
\hline 23 & 13000 & .93 & .02 & .6 \\
\hline 24 & 14000 & .94 & .01 & .3 \\
\hline 25 & 15000 & .95 & .01 & .3 \\
\hline 26 & 16000 & .96 & .01 & .3 \\
\hline 27 & 17000 & .97 & .01 & .3 \\
\hline 28 & 20000 & .98 & .01 & .3 \\
\hline 29 & $\infty$ & 1.00 & .02 & .6 \\
\hline
\end{tabular}

Since the theoretical or expected absolute frequency in each class should be equal to or greater than five, it is necessary to combine some of the classes to meet this condition. Combining certain classes gives the results shown in Table II. 
'Table II. Data for Applying Chi-Square Test

\begin{tabular}{|c|c|c|c|}
\hline $\begin{array}{c}\text { Class } \\
\mathrm{j}\end{array}$ & $\begin{array}{l}\text { Upper limit } \\
\text { of Class } \\
\text { interval }\end{array}$ & $\begin{array}{l}\text { Theoretical } \\
\text { Absolute } \\
\text { Frequency }\left(\mathrm{E}_{\mathrm{j}}\right)\end{array}$ & $\begin{array}{l}\text { Observed } \\
\text { Absolute } \\
\text { Frequency }\left(0_{\mathrm{j}}\right)\end{array}$ \\
\hline 1 & 1000 & 5.4 & 4 \\
2 & 2500 & 6.3 & 4 \\
3 & 4500 & 6.0 & 8 \\
4 & 7500 & 5.7 & 5 \\
5 & $\infty$ & 6.6 & 9 \\
\hline
\end{tabular}

The calculated value of chi-square is determined by

$$
\begin{gathered}
\chi^{2}=\sum_{j=1}^{k} \frac{\left(0_{j}-E_{j}\right)^{2}}{E_{j}} \\
=\frac{(4-5.4)^{2}}{5.4}+\frac{(4-6.3)^{2}}{6.3}+\frac{(8-6.0)^{2}}{6.0}+\frac{(5-5.7)^{2}}{5.7}+\frac{(9-6.6)^{2}}{6.6} \\
=0.363+0.840+0.667+0.086+1.105 \\
\chi^{2}=3.061
\end{gathered}
$$

The critical value for chi-square is

$$
\chi_{\mathrm{d}, \alpha}^{2}=\chi_{3,0.20}^{2}=4.642
$$

where the degrees of freedom are determined as

$\mathrm{d}=\mathrm{k}-1-\mathrm{h}=5-1-1=3$.

The value of one is assigned to $\mathrm{h}$ since only one parameter was estimated from the data.

Since the calculated value of chi-square is less than the critical value, the hypothesis that the data came from an exponential distribution is not 
rejected. This indicates that it is reasonable to use the exponential function as the reliability function for the component on which the data were collected.

\section{Component Reliabilities for the Electrical Power System}

The component reliabilities for components in the electrical power system have been computed based on the data in a report on similar components operating in a similar environment. ${ }^{10}$ Since the data provide mean-timebetween failures (m) and failure rates $(\lambda)$, it is evident that the exponential function has been established as the reliability function for the components.

Table III provides for each component in the system the appropriate name, the mean-time-between failures $(m)$ in hours or cycles, the failure rate $(\lambda)$ in failures per hour, and the computed reliability.

The component reliabilities have been computed based on an operating time of one hour. This is a reasonable time to use in view of the typical onehour flights expected for a small twin-engine passenger plane. Components which are cycle sensitive are considered to cycle twice during a flight. The failure rate entered in Table III is appropriately adjusted for these items.

${ }^{10}$ J. J. Cyran, Electrical Power System Failure Rates, Engineering Report No. RE-103, Douglas Aircraft Co., Long Beach, California (January 1966). 
Table III. Component Data for Electrical Power System

\begin{tabular}{|l|c|c|c|}
\hline Component & $\begin{array}{c}\mathrm{m} \\
\text { (hours or } \\
\text { cycles) }\end{array}$ & $\begin{array}{c}\lambda \\
\text { (per hour) }\end{array}$ & Reliability \\
\hline $\begin{array}{l}\text { Generator } \\
\text { Generator }\end{array}$ & 2,500 hours & 0.000400 & 0.999600 \\
$\begin{array}{l}\text { AC Cross } \\
\text { Tie Relay }\end{array}$ & 31,544 cycles & 0.000063 & 0.999937 \\
$\begin{array}{l}\text { Any Bus } \\
\text { AC Ground } \\
\text { Service Tie } \\
\text { Relay }\end{array}$ & 500,000 hours & 0.000002 & 0.999900 \\
$\begin{array}{l}\text { Transformer } \\
\text { Rectifier } \\
\text { (T-R) }\end{array}$ & 10,137 cycles & 0.000197 & 0.999998 \\
$\begin{array}{l}\text { Reverse } \\
\text { Current } \\
\text { Relay }\end{array}$ & 215,666 hours & 0.000109 & 0.999800 \\
$\begin{array}{l}\text { DC Ground } \\
\text { Service Tie } \\
\text { Relay }\end{array}$ & 25,000 hours & 0.000004 & 0.999995 \\
$\begin{array}{l}\text { DC Cross } \\
\text { Tie Relay }\end{array}$ & 23,177 cycles & 0.000086 & 0.99999914 \\
\hline
\end{tabular}


CHAPTER V. FURTHER ANALYSIS OF COMPLEX SYSTEMS

$\underline{\text { Introduction }}$

In Chapter III, it was pointed out that using the canonical expansion scheme to determine the system reliability equation becomes prohibitive when the system has a large number of components and the component probabilities of failure are not small. When this situation occurs, the sum of the numerical evaluations for the first few success terms does not provide a sufficiently good approximation.

To illustrate this point, consider the system shown in Figure 5, Chapter III. The expansion scheme for this system contains only 32 items. For the electrical power system, however, the complete expansion would require 4096 terms. Although identifying success terms in the expansion would be easy, obtaining the expansion itself would require a tremendous amount of labor.

\section{A Method for Determining the System Reliability Equation}

When conditions are such that the canonical expansion scheme is not very attractive, the system reliability equation can be obtained by defining pertinent events for the system. These events may be output events representing outputs from the terminal components of the system, or they may represent outputs from components internal to the system. 
After these events are defined, equations are written expressing the probability of their occurrence. The probability of getting output events from internal components is written in terms of the preceding components. The probabilities of getting output events from terminal components are written in terms of the probability of occurrence of the outputs from internal components and in terms of the reliabilities of certain components as necessary. The primary reason for defining output events from certain internal components is to simplify writing the initial equation for the system reliability. After the above is accomplished, the system reliability equation is then written in terms of the probability of occurrence of the events defined in terms of outputs from terminal components.

This method will be demonstrated first on the system shown in Figure 5, Chapter III. Success is achieved for this system if there is an output from component 4 , or component 5 , or both. The complete reliabiity function was derived for this system and is given in Chapter III.

Let the following events be defined:

Event $A=$ output from component 4 , and

Event $\mathrm{B}=$ output from component 5 .

If an expression can be derived for the probability of occurrence of the events $\mathrm{A}$ and $\mathrm{B}$, then the system reliability equation can be determined as

$$
R_{S}=\operatorname{Pr}(A)+\operatorname{Pr}(B)-\operatorname{Pr}(A) \operatorname{Pr}(B) .
$$


The equations for the probability of occurrence of events A and B are given below:

$$
\begin{aligned}
& \operatorname{Pr}(A)=\left[R_{2} R_{3}\left(1-R_{1}\right)+R_{1}\right] R_{4} \\
& \operatorname{Pr}(B)=\left[R_{1} R_{3}\left(1-R_{2}\right)+R_{2}\right] R_{5} .
\end{aligned}
$$

The system reliability equation is then determined as

$$
\begin{aligned}
& R_{s}=\left[R_{2} R_{3}\left(1-R_{1}\right)+R_{1}\right] R_{4}+\left[R_{1} R_{3}\left(1-R_{2}\right)+R_{2}\right] R_{5} \\
& -\left\{\left[R_{2} R_{3}\left(1-R_{1}\right)+R_{1}\right] R_{4}\right\} \quad\left\{\left[R_{1} R_{3}\left(1-R_{2}\right)+R_{2}\right] R_{5}\right\} \\
& R_{s}=R_{2} R_{3} R_{4}-R_{1} R_{2} R_{3} R_{4}+R_{1} R_{4}+R_{1} R_{3} R_{5}-R_{1} R_{2} R_{3} R_{5}+R_{2} R_{5}-R_{1} R_{2} R_{3}{ }^{2} R_{4} R_{5} \\
& +R_{1} R_{2}{ }^{2} R_{3}{ }^{2} R_{4} R_{5}-R_{2}{ }^{2} R_{3} R_{4} R_{5}+R_{1}{ }^{2} R_{2} R_{3}{ }^{2} R_{4} R_{5}-R_{1}{ }^{2} R_{2}{ }^{2} R_{3}{ }^{2} R_{4} R_{5}+R_{1} R_{2}{ }^{2} R_{3} R_{4} R_{5} \\
& -R_{1}{ }^{2} R_{3} R_{4} R_{5}+R_{1}{ }^{2} R_{2} R_{3} R_{4} R_{5}-R_{1} R_{2} R_{4} R_{5} .
\end{aligned}
$$

This equation can be simplified by using one of the fundamental laws from Boolean algebra. The law is

$$
\mathrm{x}^{2}=\mathrm{x} .^{1}
$$

As related to the above equation, this can be interpreted as follows: the probability that a particular component works times the probability that same component works simultaneously is in reality just the probability that the component works. Thus, in the above equation,

$$
R_{1}^{2}=R_{1}, R_{2}^{2}=R_{2} \text {, etc. }
$$

With this relationship, the equation can be written as

$$
\begin{aligned}
& R_{S}=R_{2} R_{3} R_{4}-R_{1} R_{2} R_{3} R_{4}+R_{1} R_{4}+R_{1} R_{3} R_{5}-R_{1} R_{2} R_{3} R_{5}+R_{2} R_{5}-R_{1} R_{2} R_{3} R_{4} R_{5} \\
& +R_{1} R_{2} R_{3} R_{4} R_{5}-R_{2} R_{3} R_{4} R_{5}+R_{1} R_{2} R_{3} R_{4} R_{5}-R_{1} R_{2} R_{3} R_{4} R_{5}+R_{1} R_{2} R_{3} R_{4} R_{5}
\end{aligned}
$$

${ }^{1}$ C. I. Lewis, A Survey of Symbolic Logic, Dover Publications, Inc. , New York, N. Y., 1960, p. 54. 
$-R_{1} R_{3} R_{4} R_{5}+R_{1} R_{2} R_{3} R_{4} R_{5}-R_{1} R_{2} R_{4} R_{5}$

The equation can now be simplified and written as

$R_{S}=R_{1} R_{4}+R_{2} R_{5}+R_{1} R_{3} R_{5}+R_{2} R_{3} R_{4}-R_{1} R_{2} R_{3} R_{4}-R_{1} R_{2} R_{3} R_{5}-R_{1} R_{2} R_{4} R_{5}$

$-R_{1} R_{3} R_{4} R_{5}-R_{2} R_{3} R_{4} R_{5}+2 R_{1} R_{2} R_{3} R_{4} R_{5}$.

This is the same equation that was obtained from the complete expansion in Chapter III and thus demonstrates the validity of this method. It should be pointed out that if two or more factors in an equation contain terms involving some components which are the same, and multiplication of these factors is indicated, then the multiplication must be performed and the resulting expression simplified by applying the fundamental Boolean law.

Application of the Method to the Electrical Power System

The method that has just been demonstrated in the previous section can now be applied to the electrical power system.

Reference to Figure 6, Chapter III, indicates that success is achieved for the electrical power system if there is an output from component 8 or 10 or both, and from component 11 or 12 or both. Let the following events be defined:

Event $\mathrm{E}=$ output from component 4 , Event $F=$ output from component 5, Event $\mathrm{AC}=$ output from component 8 or 10 or both, and Event DC = output from component 11 , or 12 , or both. 
An expression can be derived for the probability of occurrence of each of the above events. For the event $\mathrm{E}$, the equation is

$$
\begin{aligned}
& R_{E}=\left[R_{2} R_{3}\left(1-R_{1}\right)+R_{1}\right] R_{4} \\
& R_{E}=R_{1} R_{4}+R_{2} R_{3} R_{4}-R_{1} R_{2} R_{3} R_{4} .
\end{aligned}
$$

For the event $\mathrm{F}$, the equation is

$$
\begin{aligned}
& R_{F}=\left[R_{1} R_{3}\left(1-R_{2}\right)+R_{2}\right] R_{5} \\
& R_{F}=R_{2} R_{5}+R_{1} R_{3} R_{5}-R_{1} R_{2} R_{3} R_{5} .
\end{aligned}
$$

For the event $\mathrm{AC}$, the equation is

$$
R_{A C}=R_{E} R_{8}+R_{F} R_{10}-R_{E} R_{8} R_{F} R_{10} .
$$

For the event $\mathrm{DC}$, the equation is

$$
\begin{aligned}
& R_{D C}=R_{E} R_{6} R_{11}+R_{F} R_{7} R_{12}+R_{E} R_{6} R_{9} R_{12}+R_{F} R_{7} R_{9} R_{11}-R_{E} R_{6} R_{F} R_{7} R_{9} R_{11} \\
& -R_{E} R_{6} R_{F} R_{7} R_{9} R_{12}-R_{E} R_{6} R_{F} R_{7} R_{11} R_{12}-R_{E} R_{6} R_{9} R_{11} R_{12}-R_{F} R_{7} R_{9} R_{11} R_{12} \\
& +2 R_{E} R_{6} R_{F} R_{7} R_{9} R_{11} R_{12} .
\end{aligned}
$$

The system reliability equation is then determined as

$$
\begin{aligned}
& R_{S}=R_{A C} R_{D C}=R_{E} R_{6} R_{8} R_{11}+R_{E} R_{F} R_{7} R_{8} R_{12}+R_{E} R_{6} R_{8} R_{9} R_{12}+R_{E} R_{F} R_{7} R_{8} R_{9} R_{11} \\
& -R_{E} R_{F} R_{6} R_{7} R_{8} R_{9} R_{11}-R_{E} R_{F} R_{6} R_{7} R_{8} R_{9} R_{12}-R_{E} R_{F} R_{6} R_{7} R_{8} R_{11} R_{12}-R_{E} R_{6} R_{8} R_{9} R_{11} R_{12} \\
& -R_{E} R_{F} R_{7} R_{8} R_{9} R_{11} R_{12}+2 R_{E} R_{F} R_{6} R_{7} R_{8} R_{9} R_{11} R_{12}+R_{E} R_{F} R_{6} R_{10} R_{11}+R_{F} R_{7} R_{10} R_{12} \\
& +R_{E} R_{F} R_{6} R_{9} R_{10} R_{12}+R_{F} R_{7} R_{9} R_{10} R_{11}-R_{E} R_{F} R_{6} R_{7} R_{9} R_{10} R_{11}-R_{E} R_{F} R_{6} R_{7} R_{9} R_{10} R_{12} \\
& -R_{E} R_{F} R_{6} R_{7} R_{10} R_{11} R_{12}-R_{E} R_{F} R_{6} R_{9} R_{10} R_{11} R_{12}-R_{F} R_{7} R_{9} R_{10} R_{11} R_{12} \\
& +2 R_{E} R_{F} R_{6} R_{7} R_{9} R_{10} R_{11} R_{12}+R_{E} R_{F} R_{7} R_{8} R_{9} R_{10} R_{11} R_{12}-2 R_{E} R_{F} R_{6} R_{7} R_{8} R_{9} R_{10} R_{11} R_{12} \\
& -R_{E} R_{F} R_{6} R_{8} R_{10} R_{11}-R_{E} R_{F} R_{7} R_{8} R_{10} R_{12}-R_{E} R_{F} R_{6} R_{8} R_{9} R_{10} R_{12}-R_{E} R_{F} R_{7} R_{8} R_{9} R_{10} R_{11} \\
& +R_{E} R_{F} R_{6} R_{7} R_{8} R_{9} R_{10} R_{11}+R_{E} R_{F} R_{6} R_{7} R_{8} R_{9} R_{10} R_{12}+R_{E} R_{F} R_{6} R_{7} R_{8} R_{10} R_{11} R_{12} \\
& +R_{E} R_{F} R_{6} R_{8} R_{9} R_{10} R_{11} R_{12} .
\end{aligned}
$$


It is more convenient to obtain a numerical estimate of the system reliability for a specific operating time by first computing the values for $R_{E}$, $R_{F}, R_{E} R_{F}, R_{6}$, and $R_{7}$, and then substituting them into the above equation. The expression for $R_{E}$ was

$$
R_{E}=R_{1} R_{4}+R_{2} R_{3} R_{4}-R_{1} R_{2} R_{3} R_{4} .
$$

Substituting the component reliability functions with the appropriate parameters (established in Chapter IV) gives $R_{E}=e^{-465 \times 10^{-6} t}+e^{-574 \times 10^{-6} t}-e^{-1037 \times 10^{-6} t}$.

The expression for $R_{F}$ was

$$
R_{F}=R_{2} R_{5}+R_{1} R_{3} R_{5}-R_{1} R_{2} R_{3} R_{5} .
$$

Making the appropriate substitutions gives $R_{F}=e^{-465 \times 10^{-6} t}+e^{-574 \times 10^{-6} t}-e^{-1037 \times 10^{-6} t}$.

The expression for $R_{E} R_{F}$ is

$R_{E} R_{F}=R_{1} R_{2} R_{4} R_{5}+R_{1} R_{3} R_{4} R_{5}+R_{2} R_{3} R_{4} R_{5}-2 R_{1} R_{2} R_{3} R_{4} R_{5}$.

Making the appropriate substitutions gives

$R_{E} R_{F}=e^{-930 \times 10^{-6} t}+2 e^{-576 \times 10^{-6} t}-2 e^{-1039 \times 10^{-6} t}$

The logic component number six is made up of two parallel branches as can be seen from Figure 4, Chapter III. Let branch "a" denote the branch consisting of the AC ground service tie relay, ground AC bus, right transformer-rectifier No. 2, reverse current relay, and DC ground service tie relay. Let branch " $b$ " denote the branch consisting of the right transformerrectifier No. 1 and a reverse current relay. The expression for $R_{6}$ can then be written as 


$$
R_{6}=R_{a}+R_{b}-R_{a} R_{b}
$$

The appropriate substitution gives

$R_{6}=e^{-294 \times 10^{-6} t}+e^{-9 \times 10^{-6} t}-e^{-303 \times 10^{-6} t}$.

For the logic component number seven, branches "c" and " $d$ " can be defined in a similar manner. The expression for $R_{7}$ can then be written as

$$
\mathrm{R}_{7}=\mathrm{R}_{\mathrm{c}}+\mathrm{R}_{\mathrm{d}}-\mathrm{R}_{\mathrm{c}} \mathrm{R}_{\mathrm{d}}
$$

The appropriate substitution gives

$$
R_{7}=2 e^{-9} \times 10^{-6} t-e^{-18 \times 10^{-6} t}
$$

In the system reliability equation, those portions of the terms which consist of combinations of the components 8 through 12 can be combined readily by summing their exponents. After this is accomplished, the system reliability equation would be

$$
\begin{aligned}
& R_{S}=R_{E} R_{6} e^{-4 \times 10^{-6} t}+R_{E} R_{F} R_{7} e^{-4 \times 10^{-6} t}+R_{E} R_{6} e^{-90 \times 10^{-6} t}+R_{E} R_{F} R_{7} e^{-90 \times 10^{-6} t} \\
& -4 R_{E} R_{F} R_{6} R_{7} e^{-90 \times 10^{-6} t}-2 R_{E} R_{F} R_{6} R_{7} e^{-6 \times 10^{-6} t}-R_{E} R_{6} e^{-92 \times 10^{-6} t} \\
& -R_{E} R_{F} R_{7} e^{-92 \times 10^{-6} t}+R_{E} R_{F} R_{6} e^{-4 \times 10^{-6} t}+R_{F} R_{7} e^{-4 \times 10^{-6} t}+R_{E} R_{F} R_{6} e^{-90 \times 10^{-6} t} \\
& +R_{F} R_{7} e^{-90 \times 10^{-6} t}-R_{E} R_{F} R_{6} e^{-92 \times 10^{-6} t}-R_{F} R_{7} e^{-92 \times 10^{-6} t}-R_{E} R_{F} R_{6} e^{-6 \times 10^{-6} t} \\
& -R_{E} R_{F} R_{7} e^{-6 \times 10^{-6} t}-R_{E} R_{F} R_{6} e^{-92 \times 10^{-6} t}-R_{E} R_{F} R_{7} e^{-92 \times 10^{-6} t} \\
& +6 R_{E} R_{F} R_{6} R_{7} e^{-92 \times 10^{-6} t}+R_{E} R_{F} R_{6} R_{7} e^{-8 \times 10^{-6} t}+R_{E} R_{F} R_{6} e^{-94 \times 10^{-6} t} \\
& +R_{E} R_{F} R_{7} e^{-94 \times 10^{-6} t}-2 R_{E} R_{F} R_{6} R_{7} e^{-94 \times 10^{-6} t}
\end{aligned}
$$


CHAPTER VI. IMPLEMENTING, CONTROLLING, AND TESTING THE SOLUTION

Implementation and Controls for the Solution

As discussed in Chapter $I$, the major problem confronting engineering management is that of selecting a particular design from several proposed design concepts based on established criteria. The criteria for selection might be based on such elements as cost, weight, performance, and reliability.

After one concept is selected, implementation takes place which consists of the complete development of the chosen design. This will determine whether or not the design concept is valid from a functional standpoint and if the design meets the established criteria.

Controls for the solution consist of maintaining a record as to how well the design is meeting the established criteria throughout its development. From the standpoint of reliability, if the initial design configuration is changed, the reliability must be estimated again to determine the effect of the change. If the reliability estimate decreases significantly, engineering management should be made aware of the decrease and the designers may be asked to attempt to improve the design. 


\section{Testing the Solution}

Except in unusual cases, the reliability of a system cannot be estimated from testing until the system has been put into actual operation. Even then, for complex systems, it may not be possible to get an estimate of the system reliability until the system has benn operated for many thousands of hours.

When the latter occurs, it is possible in a much shorter time to obtain reliability estimates of at least some of the components that make up the system. These component reliability estimates, based on actual operating experience, can then be used in the system reliability equation to obtain an estimate of the system reliability. These updated evaluations can then be compared with the initial predictions. 


\section{CHAPTER VII. CONCLUSIONS AND RECOMMENDATIONS}

Conclusions

As proposed in Chapter I, this study has been confined to a subproblem of a major problem. The major problem was viewed as that of selecting one particular design from several proposed design concepts based on established criteria. The subproblem as treated here was that of estimating the reliability of the proposed concepts, with particular emphasis on complex systems.

In Chapter II, the analysis of simple systems was discussed. When a system is studied for a reliability analysis, a reliability logic diagram is constructed that shows the reliability relationship of the components that make up the system. When this diagram resulted in a simple series, parallel, or series-parallel configuration, the system was viewed as a simple system. The system reliability equation for such a system can be written by a relatively easy application of the fundamental probability theorems.

When the reliability logic diagram did not result in one of the above mentioned configurations, the system was viewed as a complex system. In Chapter III, a canonical expansion scheme technique was used to estimate the reliability of a complex system when the system has a relatively small number of components or the component probabilities of failure are small. At this point, the reliability functions for the components that make up a system were discussed in Chapter IV. 
If the number of components in a system is rather large and the component probabilities of failure are not small, the expansion technique becomes too cumbersome as the number of terms involved grows considerably. When this situation arises, a method can be used which was developed in Chapter V to obtain the complete system reliability equation. This method was seen to depend primarily on defining pertinent output events for the system.

Finally, a limited discussion was provided in Chapter VI on implementing, controlling, and testing the solution in regard to reliability.

\section{$\underline{\text { Recommendations }}$}

When a system is determined to be complex and the number of components is small or the component probabilities of failure are small, the canonical expansion method is recommended for use as it will provide the system reliability estimate fairly quickly. If, however, the number of components is large and the component probabilities of failure are not small, it is recommended that the method developed in Chapter $\mathrm{V}$ be used.

When the components that make up a system are similar to components that have operational experience in environments similar to those expected, then sufficient data are usually available to obtain reliability estimates for the components. If a component is of a research and development nature, however, sufficient data are not usually available from testing to obtain a reasonable reliability estimate. The optimum method of testing would be to simulate simultaneously as many of the expected environments as possible. 
Since this is usually too expensive, a study should be made on how reliability tests can be conducted on components without the simultaneous simulation of the expected environments over a long period of time. 


\section{BI BLIOGRAPHY}

\section{Books}

Ackoff, Russell L. Scientific Method. New York and London: John Wiley \& Sons, Inc. , 1962.

Barlow, R. E. , and Proschan, F. Mathematical Theory of Reliability.

New York, London, and Sidney: John Wiley \& Sons, Inc. , 1965.

Bazovsky, Igor. Reliability Theory and Practice. Englewood Cliffs, New Jersey: Prentice-Hall, Inc., 1961.

Calabro, S. R. Reliability Principles and Practices. New York, Toronto, and London: McGraw-Hill Book Company, Inc., 1962.

Chorafas, Dimitris N. Statistical Processes and Reliability Engineering. New York, Toronto, and London: D. Van Nostrand Company, Inc. , 1960

Churchman, C. W. , Ackoff, R. L., and Arnoff, E. L. Introduction to Operations Research. New York: John Wiley \& Sons, Inc., 1957.

Hoel, Paul G. Introduction to Mathematical Statistics. New York, London, and Sydney: John Wiley \& Sons, 1962.

Ireson, W. Grant (Editor). Reliability Handbook. New York and London: McGraw-Hill Book Company, Inc. , 1966.

Lewis, C. I. A Survey of Symbolic Logic. New York: Dover Publications, Inc. , 1960.

Lindgren, B. W. , and McElrath, G. W. Introduction to Probability and Statistics. New York: The Macmillan Company, 1959.

Lloyd, David K. , and Lipow, Myron. Reliability: Management, Methods, and Mathematics. Englewood Cliffs, New Jersey: Prentice-Hall, Inc., 1962.

Sokolnikoff, I. S. , and Redheffer, R. M. Mathematics of Physics and Modern Engineering. New York, Toronto, and London: McGraw-Hill Book Company, Inc., 1958. 
Spiegel, Murray R. Theory and Problems of Statistics. New York: Schaum Publishing Company, 1961.

Turabian, Kate L. A Manual for Writers of Term Papers, Theses, and Dissertations. Chicago and London: The University of Chicago Press, 1955.

\section{Articles}

Davis, D. J. "An Analysis of Some Failure Data," American Statistical Association Journal (June, 1952), pp. 113-150.

English, J. Morley. "Understanding the Engineering Design Process," Journal of Industrial Engineering, vol. XV, no. 6 (November - December, 1964), pp. 291-296.

Epstein, Benjamin, and Sobel, Milton. "Life Testing," American Statistical Association Journal (September, 1953), pp. 486-502.

Gordy, Harold M. "Predicting System Reliability, "International Science and Technology (July, 1963), pp. 72-78.

\section{Documents and Reports}

Bredemann, Richard V. Reliability Model of a Complex System. St. Louis, Missouri: The Emerson Electric Mfg. Company, 1964.

Cooke, James R., Lee, Mark T., and Vanderbeck, John P. Binomial Reliability Table. China Lake, California: U. S. Naval Ordnance Test Station, January, 1964.

Cyran, J. J. Electrical Power System Failure Rates, Engineering Report No. RD-103. Long Beach, California: Douglas Aircraft Co., January, 1966.

Douglas Aircraft Co. DC-9 Electrical System Fault Analysis, Engineering Report No. LB-32161. Long Beach, California: Douglas Aircraft Co., April, 1965.

Firstman, Sidney I. Reliability Estimating By The Use of Random Sampling Simulation. Santa Monica, California: The Rand Corporation, October, 1958. 
Griffin, Marvin A. Elements of Simulation Models Using the Monte Carlo Method. University, Alabama: Industrial Engineering Department, July, 1966 (A report presented before the Huntsville, Alabama, Chapter of the American Institute of Industrial Engineers).

Hershkowitz, B. H., Wheelock, M. E., and Maher, D. P. Reliability Simulation Model. Downey, California: North American Aviation, Inc.

Pieruschda, E. G. Sense and Nonsense in the Application of the Monte Carlo Method in Reliability Theory. Sunnyvale, California: Lockheed Missiles and Space Company, August, 1963.

U. S. Department of Commerce. Tables of the Exponential Function $\mathrm{e}^{\mathrm{x}}$. National Bureau of Standards Applied Mathematics Series 14. Washington: U. S. Government Printing Office, January, 1961. 


\author{
APPROVAL \\ ESTIMATING RELIABILITY OF COMPLEX SYSTEMS \\ By \\ Robert H. Ailor
}

The information in this report has been reviewed for security classification. Review of any information concerning Department of Defense or Atomic Energy Commission programs has been made by the MSFC Security Classification Officer. This report, in its entirety, has been determined to be unclassified.

This document has also been reviewed and approved for technical accuracy.

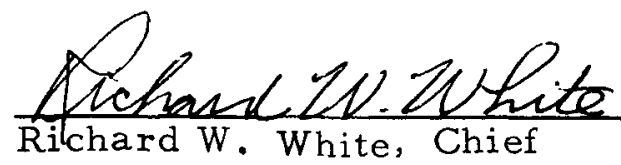

Reliability Engineering Branch

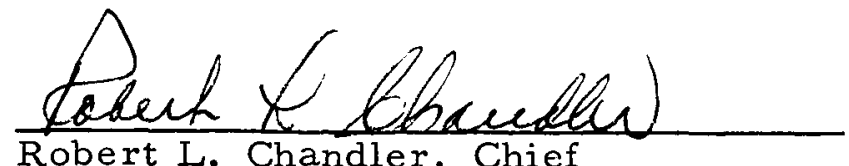

Robert L. Chandler, Chief

Reliability Assurance Division

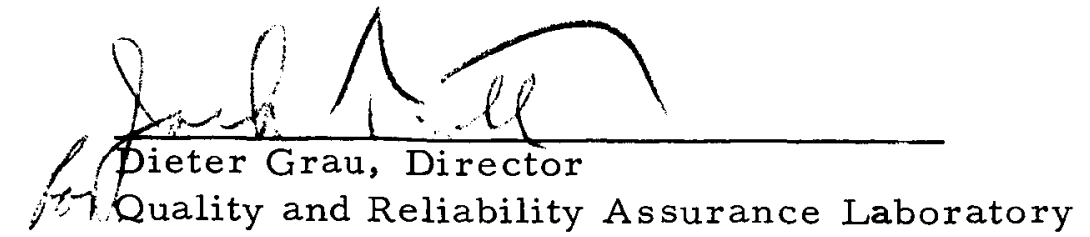




\section{DISTRIBUTION}

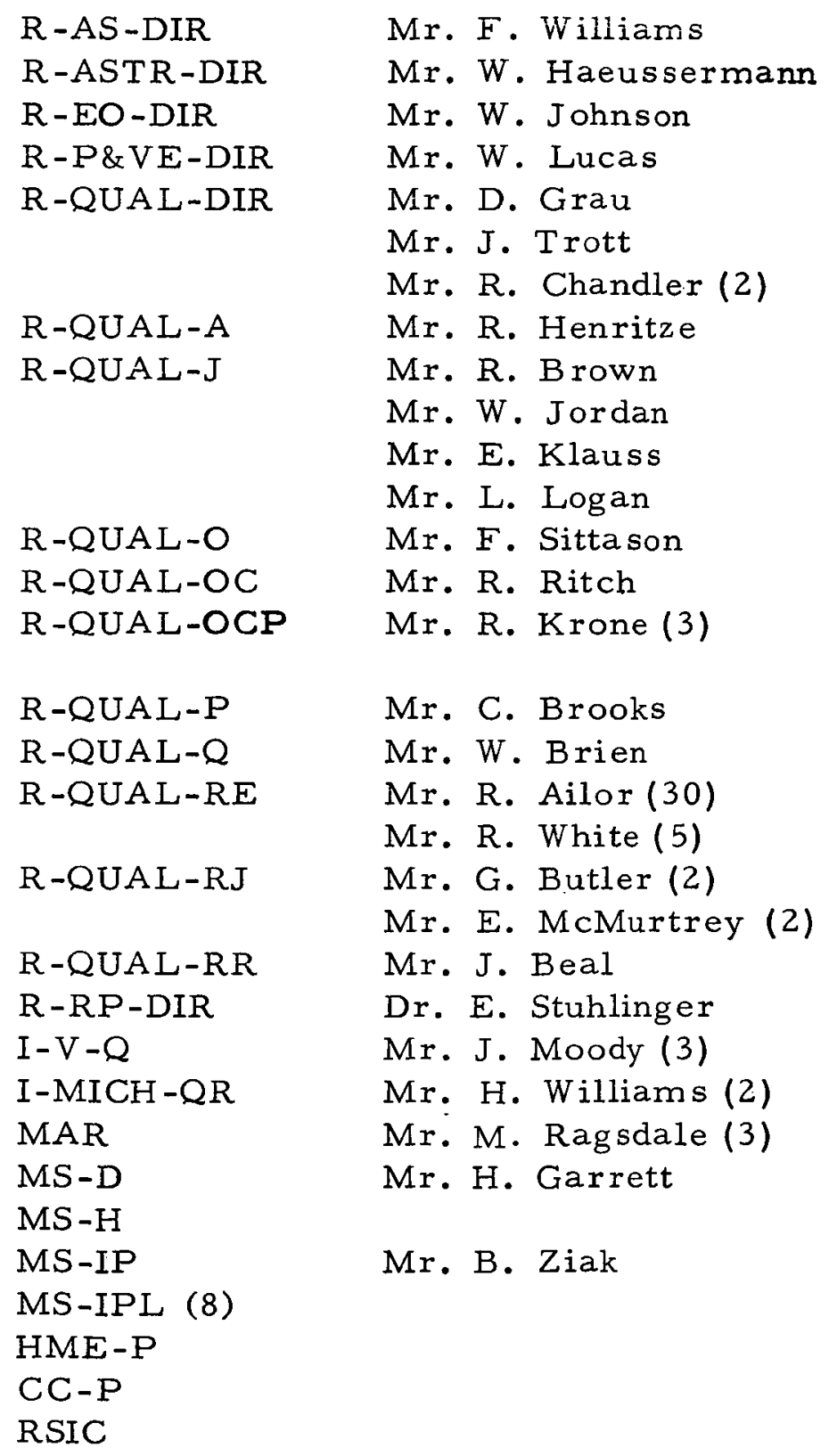

Scientific \& Technical Information Division (25) Attn: NASA Representative (S-AK/RKT) P.O. Box 5700 Bethesda, Maryland 